Adriana D. C. Costa

\title{
Anatomia da madeira em Sapotaceae
}

Tese apresentada ao Instituto de Biociências da Universidade de São Paulo para obtenção do título de Doutor em Ciências, na Área de Botânica.

Orientadora: Profa. Dra. Veronica Angyalossy

São Paulo

2006 


\section{Ficha Catalográfica}

\section{Costa, Adriana}

Anatomia da madeira em Sapotaceae

200p.

Tese (Doutorado) - Instituto de Biociências da

Universidade de São Paulo. Departamento de Botânica.

1. Sapotaceae 2. Anatomia da madeira 3.

Espécies neotropicais. 4. Grupamento de espécies.

Universidade de São Paulo. Instituto de Biociências.

Departamento de Botânica.

Comissão Julgadora:

$\operatorname{Prof(a).} \operatorname{Dr}(a)$.

Prof(a). $\operatorname{Dr}(a)$.
$\operatorname{Prof(a).} \operatorname{Dr}(a)$.

$\operatorname{Prof(a).} \operatorname{Dr}(a)$.

Profa. Dra. Veronica Angyalossy

Orientador(a) 
Agradecimentos 


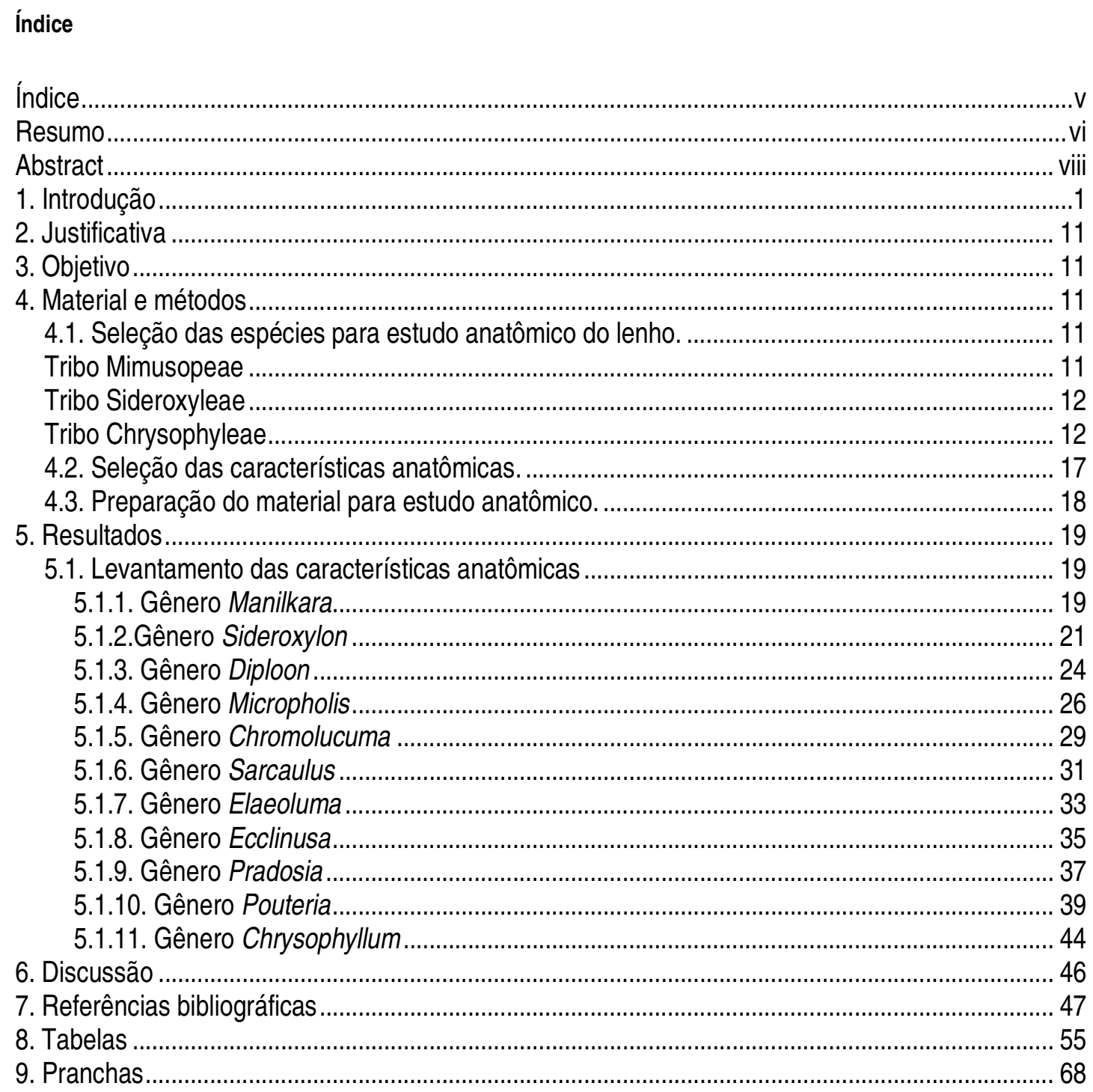




\section{Resumo}

Este trabalho apresenta o levantamento anatômico da madeira de 107 espécies distribuídas em 11 gêneros pertencentes à família Sapotaceae (ordem Ericales), do continente americano, dentre os quais Manilkara Adanson, Sideroxylon Linnaeus, Micropholis (Grisebach) Pierre,

Chromolucuma Ducke, Sarcaulus Radkolfer, Elaeoluma Baillon, Pouteria Aublet, Chrysophyllum Linnaeus, Ecclinusa Martius, Pradosia Liais e Diploon Cronquist. Na mais recente tentativa de classificação, Pennington $(1990,1991)$ reconheceu cinco tribos com base, principalmente, em características da flor e da semente. De acordo com o próprio pesquisador, quatro das tribos representariam grupos naturais, provavelmente monofiléticos. Entretanto Swenson \& Anderberg (2005), utilizando a análise molecular combinada com características morfológicas, concluíram que os dois maiores gêneros da família, Chrysophyllum e Pouteria são polifiléticos. Desse modo, a família Sapotaceae necessita de uma revisão e inúmeros autores (Record, 1939; Kukachka, 1978a) mencionaram a necessidade de mais informações anatômicas do xilema para complementar e ampliar os estudos taxonômicos e filogenéticos. Portanto, este trabalho tem como objetivo verificar se a anatomia da madeira corrobora a classificação proposta por Pennington em 1990 e a obtenção de informações que possibilitem indicar características anatômicas de valor diagnóstico e estatístico, buscando contribuir com estudos futuros no agrupamento das espécies brasileiras associadas com as africanas e asiáticas da família. A descrição da anatomia da madeira segue a terminologia adotada pelo comitê da Associação Internacional dos Anatomistas de Madeira (IAWA Committee 1989). O resultado obtido pela estatística indica a formação de oito grupos que apresentam similaridades quanto ao tipo de parênquima axial, diâmetro dos vasos, diâmetro das pontoações intervasculares, tipo e localização das pontoações raio-vasculares e das inclusões minerais como, cristais prismáticos, estiloidais e areniformes, assim como dos corpos silicosos. Tais características agrupam gêneros e espécies afins com significância estatística. Conclui-se que a anatomia da madeira apresenta valor de diagnose para os diferentes gêneros, e que, em muitos casos, não corrobora a classificação proposta por Pennington $(1990,1991)$ na última revisão taxonomica da família. 



\section{Abstract}

This work presents the anatomical hoist of the wood of 107 species distributed in 11 belonging kinds to the family Sapotaceae (order Ericales), of the American continent, among the which Manilkara Adanson, Sideroxylon Linnaeus, Micropholis (Grisebach) Pierre, Chromolucuma Ducke, Sarcaulus Radkolfer, Elaeoluma Baillon, Pouteria Aublet, Chrysophyllum Linnaeus, Ecclinusa Martius, Pradosia Liais and Diploon Cronquist. In the most recent attempt of classification, Pennington (1990, 1991) recognized five tribes with base, mainly, in characteristics of the flower and of the seed. According to the own researcher, four of the tribes would represent natural groups, probably monofiléticos. However Swenson \& Anderberg (2005), utilizing the molecular analysis combined with characteristics morfológicas, concluded that the two biggest kinds of the family, Chrysophyllum and Pouteria are polifiléticos. Of that way, the family Sapotaceae needs a revision and endless number authors (Record, 1939; Kukachka, 1978a) mentioned the need of more anatomical information of the xilema for complementary and extend the studies taxonômicos and filogenéticos. Therefore, this work has like objective verify itself the anatomy of the wood corroborates the classification proposal by Pennington in 1990 and the obtaining of information that are going to indicate worthy anatomical characteristics diagnosis and statistical, seeking contribute with future studies in the group of the Brazilian species associated with the Africans and Asians of the family. The description of the anatomy of the wood follows the terminology adopted by the committee of the International Association of the Anatomists of Madeira (IAWA Committee 1989). The result obtained by the statistical one indicates the formation of eight groups that present similarities as regards the kind of parênquima axial, diameter of the glasses, diameter of the pontoações intervasculares, kind and location of the pontoações ray-vascular and of the mineral enclosures as, crystals prismáticos, estiloidais and areniformes, as well as of the bodies silicosos. Such characteristics group kinds and related species with significância statistical. I concluded that the anatomy of the wood presents value of diagnose for the different kinds, and that, in many cases, does not corroborate the classification proposal by Pennington $(1990,1991)$ in the last revision taxonomica of the family. 


\section{Introdução}

No Brasil, a família Sapotaceae desperta grande interesse pela importância econômica de suas madeiras, as quais freqüentemente são utilizadas na construção civil, em estruturas de telhado, assoalhos e esquadrias, assim como na fabricação de dormentes, cruzetas, móveis e obtenção de lâminas para revestimento (Mainieri \& Chimelo, 1989; Record \& Hess, 1943; SUDAM/IPT, 1981).

Os 53 gêneros e aproximadamente 1100 espécies de hábito predominantemente arbóreo, estão distribuídos nas florestas úmidas dos continentes americano, africano e asiático além de ilhas no Oceano Pacífico. A região neotropical abriga 11 gêneros incluindo Pouteria (188 spp.), Sideroxylon (46 spp.), Chrysophyllum (43 spp.), Micropholis (38 spp.), Manilkara (30 spp.), Pradosia (23 spp.), Ecclinusa (11 spp.), Sarcaulus (5 spp.), Elaeoluma (4 spp.), Chromolucuma (2 spp.) e Diploon (1 sp.) (Pennington, 1990, 1991).

A família é subdivida em cinco tribos: Mimusopeae, Isonandreae, Sideroxyleae, Chrysophylleae e Omphalocarpeae, de acordo com a mais recente classificação proposta por Pennington (1991).

A tribo Chrysophylleae com 19 gêneros possui maior número de representantes neotropicais, incluindo o gênero Pouteria, também de distribuição pantropical (Pennington, 1990, 1991).

Pennington $(1990,1991)$ reorganizou a família reduzindo o número de tribos e gêneros anteriormente propostos, sugerindo 53 gêneros distribuídos em cinco tribos. Aubréville (1964) descreveu 122 gêneros em 15 tribos e quatro subfamílias e Baehni (1965) reconheceu 63 gêneros em seis tribos e três subfamílias.

O problema da delimitação dos gêneros nesta família ocorre porque as características morfológicas disponíveis neste nível não representam sinapomorfias dentro do grupo, ou seja, estão presentes em vários, mas não em todos os membros de um grupo. Por isso Pennington (1990, 1991) utilizou como recurso para o agrupamento de espécies, a combinação de características de pólen, morfológicas e químicas.

Record (1939) já estava consciente sobre o problema da discordância de opiniões quanto à validade de alguns gêneros em Sapotaceae e sugeriu a utilização da anatomia da madeira para auxiliar no processo de resolução dos problemas taxonômicos. Esta opinião foi posteriormente enfatizada por Kukachka (1978a) que também criticou a sistemática da família e afirmou que a anatomia da madeira deve ser usada como ferramenta extra, em conjunto com a morfologia externa 
da planta.

Atualmente, os filogenistas moleculares discordam da classificação proposta por Pennington (1990, 1991), acreditando que as tribos e alguns gêneros como Chrysophyllum e Pouteria não constituem grupos monofiléticos.

Nos trabalhos de Morton et al. $(1996,1997)$ sobre filogenia da ordem Ebenales e da família Lecythidaceae, e no estudo de Anderberg et al. (2002) sobre filogenia da ordem Ericales, o único resultado que compartilham sobre Sapotaceae é o monofiletismo da família. Em nenhum cladograma obtido é observado o monofiletismo das tribos propostas por Pennington (1991, 1991).

Anderberg \& Swenson (2003) identificaram três possíveis linhas evolutivas na família, com base na análise da seqüência ndhFdo DNA do cloroplasto de 39 gêneros pertencentes a todos os continentes. Os autores sugeriram que o gênero Sarcosperma Hooker (que ocorre na Índia, sul da China e Malásia) seja grupo irmão do restante das Sapotaceae, que estariam distribuídas em outros dois clados, um deles constituído pelas tribos Isonandreae, Mimusopeae, Sideroxyleae + o gênero Capurodendron (posicionado na tribo Chrysophylleae por Pennington, 1991) e o outro compreenderia as tribos Chrysophylleae, Omphalocarpeae + o gênero Diploon (posicionado na tribo Sideroxyleae por Pennington, 1991).

Posteriormente, Swenson \& Anderberg (2005) usaram a análise molecular combinada com características morfológicas de praticamente o mesmo grupo de espécies do trabalho anterior. Neste estudo, eles confirmaram a diversificação basal de ambos os clados sugeridos e contribuíram com mais informações sobre as relações filogenéticas dentro destes. Um dos avanços foi a conclusão de que os gêneros Delpydora, Leptostylis, Micropholis e Pradosia constituem grupos monofiléticos e que os dois maiores gêneros da família, Chrysophyllum e Pouteria são polifiléticos. Também sugeriram que o gênero Planchonella reduzido na seção Oligotheca do gênero Pouteria deva ser restabelecido. Os mesmos autores encontraram uma indicação de que os gêneros que ocorrem na Australasia formam um grupo monofilético. Com base nestes resultados, Bartish et al., 2005 realizaram uma investigação filogenética molecular, utilizando as espécies da Nova Caledônia, com o objetivo de clarear as relações entre elas e traçar a história evolutiva do grupo. O cladograma obtido, com base na análise do DNA nuclear do ribossomo, indicou que o gênero Pouteria e Niemeyera não são monofiléticos, entretanto todas as espécies estudadas, pertencentes a estes e outros gêneros que ocorrem na Austrália, Nova Caledônia e outras ilhas vizinhas formam um grupo monofilético.

Herendeen \& Miller (2002) propuseram algumas definições e codificações dos estados das características, para utilização da anatomia da madeira em análise cladística, com base na 
terminologia adotada pelo comitê da IAWA (IAWA Committee 1989). Como conclusão desse trabalho os autores destacam, mais uma vez, a importância do uso da anatomia da madeira, incorporando esta informação na análise cladística, em conjunto com uma seleção diversificada de outras características, tais como, morfológicas, químicas e macromoleculares, podendo, desta forma, contribuir significativamente com hipóteses robustas de relações evolutivas.

Anatomia da madeira em Sapotaceae: caracterização e histórico.

Uma das mais antigas descrições do lenho de Sapotaceae, rastreada até o momento, foi publicada por Unger (1847) com a descrição do gênero Chrysophyllum (Moll \& Janssonius, 1925) e devido à dificuldade na obtenção dos trabalhos mais antigos, não foi possível verificar quais características haviam sido reconhecidas naquela época.

Nas décadas finais do século XIX e iniciais do século XX vários trabalhos em anatomia da madeira, pouco extensos, envolvendo descrições anatômicas de apenas alguns gêneros ou espécies, foram publicados. Uma exceção foi o estudo realizado por Moll \& Janssonius (1925), um dos mais importantes e extensos trabalhos da época, no qual os autores descreveram as seguintes espécies da Flora de Java: Chrysophyllum roxburghii, Sideroxylon nitidum, $S$. obovatum, $S$. argenteum, S. chrysophyllum, Mimusops elengi, Palaquium javense, P. ottolanderi, Payena suringariana e $P$. macrophylla. Também citaram uma vasta referência do final do século XIX e início do séc. XX e incluíram descrições detalhadas das espécies, inclusive com características quantitativas, sugerindo uma chave de identificação para os gêneros.

Provavelmente, Record \& Hess (1924) foram os primeiros pesquisadores que contribuíram, de forma mais relevante, com descrições anatômicas de gêneros de Sapotaceae neotropicais, pois até então a maioria dos trabalhos havia sido realizada com espécies asiáticas. Record (1939) e Record \& Hess (1943) descreveram além dos gêneros Bumelia (=Sideroxylon), Lucuma, Mimusops, Pradosia e Sideroxylon, já estudados anteriormente, mais oito gêneros de Sapotaceae do continente americano, dentre os quais: Achras (=Manilkara), Calocarpum (= Pouteria), Chromolucuma (=Pouteria), Dipholis (=Sideroxylon), Ecclinusa, Labatia (=Pouteria), Micropholis e Paralabatia (=Pouteria). 0 enfoque destes trabalhos foi a descrição anatômica das madeiras do ponto de vista tecnológico; além das descrições macro e microscópicas, incluíram informações sobre características gerais da madeira, durabilidade natural e importância comercial.

Da mesma forma como no final do século XIX, muitos pesquisadores da primeira metade do século XX se limitaram apenas a descrever anatomicamente alguns gêneros, eventualmente com propostas de chaves de identificação, contudo, não buscaram a organização da família de forma 
sistemática.

Milanez (1934) se destaca por ter descrito em detalhes a estrutura anatômica da espécie Mimusops huberi, identificada posteriormente como Manilkara huberi. Neste trabalho ele apresenta as diversas formas dos elementos de vaso e traqueídes que ocorrem no lenho, discute sobre a evolução destes elementos e cita a ocorrência de cristais nas células do parênquima axial.

Metcalfe \& Chalk (1950), no trabalho que costuma ser referência sobre descrição anatômica do lenho de inúmeras famílias botânicas na primeira metade do século XX, não opinaram com relação às questões taxonômicas, embora tenham observado o conflito existente na classificação dos gêneros da família. Adotaram como referência a classificação proposta por Baehni $(1938,1942)$ e também alguns gêneros reconhecidos por Lam (1939), sugerindo a necessidade de uma nova revisão taxonômica. Sendo assim, apesar de terem feito pequenas considerações anatômicas sobre alguns gêneros, Metcalfe \& Chalk (1950) sintetizaram de forma clara a descrição anatômica da família Sapotaceae como um todo.

Várias descrições anatômicas foram publicadas na segunda metade do século XX, mais uma vez, sobre um número restrito de espécies ou gêneros, ou ainda, sobre regiões específicas como, por exemplo: "Investigaciones anatómicas en maderas de Sapotáceas argentinas" (Cozzo, 1951); "Maderas y bosques argentinos" (Tortorelli, 1956); "Madeiras denominadas caixeta" (Mainieri, 1958); "Commercial foreign woods on the American market" (Kribs, 1959); "Bomenboek voor suriname. Herkenning van Surunaamse hout soorten aan hout en vegetatieve kenmerken" (Lindeman \& Mennega, 1963); "Descripcion y clave de maderas indigenas del Uruguay" (Tuset, 1963); "Anatomie comparée des bois d'Amérique latine et d'Afrique centrale" (Lebacq \& Staner, 1964); "Descripcion y clave macroscópicas de maderas comerciales en Uruguay" (Tuset \& Duran, 1970); "Contribuição ao estudo anatômico do lenho de cinco Sapotaceae da Amazônia" (Honda, 1971); "Plantas do Brasil. Árvores e Madeiras Úteis do Brasil. Manual de Dendrologia Básica" (Rizzini, 1978); "Anatomía de maderas de México. № 2. Veinte especies de la Selva Lacandona" (Barajas Morales et al, 1979); "Madeiras da Reserva Florestal de Curuá-Una, Estado do Pará. Caracterização anatômica, propriedades gerais e aplicações" (SUDAM/IPT, 1981); "Atlas d'identification des bois de I'Amazonie et des régions voisines" (Détienne \& Jacquet, 1983); "Legnami tropicali importati in Italia: anatomia e identificazione. I - Africa" (Nardi Berti \& Edlmann Abbate,1988); "Fichas de características das madeiras brasileiras" (Mainieri \& Chimelo, 1989); "Plant Resourses of South-East Asia - PROSEA no 5(1) - Timbers trees: major commercial timbers" (Soerianegara \& Lemmens, 1993).

Sem dúvida, o pesquisador que mais contribuiu com informações anatômicas do lenho das 
espécies de Sapotaceae neotropicais foi Kukachka que, de 1978 a 1982 publicou uma completa série de trabalhos intitulada, "Wood Anatomy of the Neotropical Sapotaceae" com descrições anatômicas detalhadas de 37 gêneros e indicação de características diagnosticas para cada um deles. $\mathrm{O}$ autor debateu as propostas de diversos taxonomistas e indicou a presença ou ausência de evidências anatômicas que sustentam a manutenção de cada gênero. Entretanto, não discutiu sobre o posicionamento dos gêneros nas subfamílias ou tribos.

Vitalis-Brun \& Mariaux (1982), em vista da homogeneidade na estrutura anatômica das madeiras de Sapotaceae, acreditaram que métodos estatísticos poderiam ser mais eficientes para sua separação do que a tradicional utilização da chave dicotômica. Estes autores estudaram 49 espécies, correspondentes a 20 gêneros da família Sapotaceae, analisando em cada espécie vinte e seis características anatômicas, que transformadas em componentes principais, foram processadas por análise fatorial discriminante, resultando em uma separação nítida de todos os gêneros analisados.

Détienne \& Jacquet (1983) descreveram 21 gêneros de Sapotaceae da Amazônia e, apesar de terem admitido a dificuldade na separação dos gêneros pela anatomia do lenho, sugeriram uma chave dicotômica de identificação microscópica para as espécies descritas. Devido ao fato da chave ter sido elaborada com características muito específicas de um número reduzido de espécies por gênero, sua utilização se tornou muito restrita.

É consenso entre os pesquisadores que o reconhecimento da família Sapotaceae, por meio das características anatômicas do lenho, é relativamente simples. Entretanto, devido à homogeneidade no nível genérico, é muito difícil distinguir os diversos gêneros e espécies.

Uma das possibilidades da existência dessa situação de homogeneidade poderia ser o fato de que a classificação inicial de determinada planta esteja incorreta, gerando conflitos na identificação. Um fato mais agravante é que os taxonomistas não chegaram a um consenso sobre quais características são importantes nos diversos níveis taxonômicos desta família, ou seja, os pesquisadores têm opiniões diferentes sobre a importância relativa das diversas características utilizadas, gerando classificações diferentes, principalmente com relação à organização geral (delimitação de subfamílias, tribos, seções, gêneros e espécies).

Desse modo a família Sapotaceae carece de estudos filogenéticos que combinem os mais diversos tipos de informação, como morfológicas, químicas, anatômicas e macromoleculares, para agrupar os indivíduos independentemente da identificação botânica dos mesmos.

A maioria das espécies de Pouteria ocorre na América do Sul, principalmente em regiões de floresta úmida baixa. No Brasil, os centros de dispersão do gênero são Amazônia, principalmente, e 
região costeira, freqüentemente ocorrendo na Bahia, Espírito Santo, Rio de Janeiro e São Paulo (Pennington, 1991).

Morfologicamente, o gênero Pouteria é caracterizado pelo hábito predominantemente arbóreo, com a ocorrência de alguns arbustos; ausência de estípulas; presença de folhas espiraladas; de quatro a seis sépalas livres, imbricadas e dispostas em um único verticilo; corola ciatiforme a tubular, com quatro a seis pétalas; estames isostêmones, opostos aos lobos da corola e inclusos nela; estaminódios alternos aos lobos da corola; ovário com um a seis -(15) lóculos e semente com cicatriz adaxial, com ou sem endosperma (Pennington, 1991).

A delimitação deste gênero é bastante complexa e ainda controversa. Baehni (1942) em sua monografia sobre o gênero Pouteria, citou 318 espécies pantropicais distribuídas em 15 seções. Aubréville $(1960,1961)$ reduziu o gênero a um número menor de espécies, restringindo sua ocorrência apenas à região neotropical.

Kukachka (1982d) criticou a circunscrição ampla proposta por Baehni, afirmando que o grupo consistiria de uma assembléia extremamente heterogênea e que uma descrição anatômica do gênero implicaria em englobar características de todas as Sapotaceae americanas. Por outro lado, concordou com o agrupamento sugerido por Aubréville, no qual o grupo resultante poderia ser caracterizado anatomicamente de acordo com o tipo de parênquima e arranjo dos vasos, reconhecendo ainda dois subgrupos de acordo com o tamanho das pontoações intervasculares.

Em sua tentativa de facilitar a identificação das espécies, Pennington $(1990,1991)$ ampliou novamente a circunscrição do gênero (aproximadamente 320 espécies) para além do continente americano, subdividindo-o em nove seções: Oligotheca, Pierrisideroxylon, Gayella, Rivicoa, Aneulucuma, Antholucuma, Pouteria, Oxythece e Franchetella. Entretanto de acordo com o próprio autor, as características que ele usou para definir seções não são muito consistentes, de forma que algumas espécies poderiam ser posicionadas em mais de uma seção.

Sendo assim, os gêneros, Barylucuma, Calocarpum, Eglerodendron, Englerella, Eremoluma, Franchetella, Gayella, Gomphiluma, Labatia, Myrtiluma, Neoxythece, Paralabatia, Podoluma, Pseudocladia, Pseudoxythece, Richardella, Sandwithiodoxa, Syzygiopsis e Urbanella caracterizados pela anatomia do lenho por Kukachka, foram reduzidos a Pouteria.

A tabela 1 ilustra os generos de Sapotaceae, no continente americano, reconhecidas por Pennington. À direita do quadro estão indicados os gêneros correspondentes descritos por Kukachka. 
Tabela 1 Cruzamento entre os gêneros de Sapotaceae neotropical estabelecidos por Pennington (1990), tendo como suporte a morfologia vegetal, e os gêneros correspondentes descritos por Kukachka (1978-1982), com base na anatomia da madeira.

\section{PENNINGTON}

M. longifolia

M. maxima

M. bidentata subsp. bidentata

M. bidentata subsp. surinamensis

M. zapota

M. chicle

M. huberi

M. inundata

M. venezuelana

S. persimile subsp. persimile

S. obovatum

S. obtusifolium subsp. buxifolium

S. celastrinum

S. cubense

S. jubilla

S. salicifolium

D. cuspidatum

M. guyanensis subsp. guyanensis

M. guyanensis subsp. Duckeana

M. crotonoides

M. egensis

M. mensalis

M. venulosa

M. crassipedicelata

M. gardneriana

M. porphyrocarpa

\section{KUKACHKA}

Tribo Mimusopeae

Manilkara

Manilkara longifolia

Nao identificada

Manilkara bidentata

M. surinamensis

M. williamii

M. negrosensis

M. solimoesensis

M. surinamensis

M. zapotilla

M. bidentata

M. elata

M. huberi

Micropholis barbourii

M. excelsa

$M$. inundata

M. albescens

Tribo Sideroxyleae

Sideroxylon

Bumelia persimilis

Bumelia obovata

Bumelia obtusifolia subsp. buxifolia

Bumelia celastrina

Dipholis cubensis

Dipholis jubilla

Dipholis salicifolia

Diploon

D. cuspidatum

Tribo Chrysophylleae

Micropholis

Micropholis cyrtobotrya

Micropholis melinonii

Micropholis williamsii

Micropholis apiculata

Micropholis duckeana

Micropholis sp.

Micropholis egensis

Micropholis martiana

Micropholis ulei

Micropholis mensalis

Micropholis venulosa

Micropholis cylindrocarpa

Micropholis sp.

Micropholis gardneriana

Micropholis spruceana

Não identificada 


\section{PENNINGTON}

KUKACHKA

cont. Micropholis

M. cylindrocarpa

M. madeirensis

M. williamii

M. splendens

C. rubriflora

S. brasiliensis subsp. brasiliensis

S. vestitus

E. glabrescens

E. glabrescens

E. guianensis

E. lanceolata

P. atroviolaceae

$P$. cochlearia subsp. praealta

$P$. schomburgkiana subsp. schomburgkiana

P. montana

P. cuatrecasii

P. colombiana

P. putamen-ovi

$P$. ramiflora

P. Iucumifolia

$P$. bilocularis

P. coriacea

$P$. egregia

P. gongrijpii

$P$. reticulata subsp. reticulata

$P$. reticulata subsp. surinamensis

P. sagotiana

$P$. retinervis

$P$. rostrata
Micropholis cylindrocarpa Micropholis spruceana M. madeirensis M. killipii

M. splendens

Chromolucuma

C. rubriflora

Sarcaulus

Micropholis ulei Ragala sp.

Pouteria vestita Não identificada

Elaeoluma

E. glabrescens Elaeoluma sp.

Ecclinusa

$$
\begin{array}{r}
\text { E. guianensis } \\
\text { Ecclinusa sp. } \\
\text { E. striata } \\
\text { E. tenuifolia }
\end{array}
$$

Pradosia

Pradosia sp.

Pradosia praealta subsp. subsessilis Glycoxylon pedicelatum

$P$. inophylla

$P$. maguirei

P. schomburgkiana

Pradosia sp.

Pradosia sp.

Pradosia sp.

Pouteria

Seção Franchetella

Não identificada

Não identificada

Pseudocladia lateriflora

Pseudocladia orinocoensis

Neoxythece sp.

Não identificada

Pseudocladia minutiflora

Sandwithiodoxa egregia

Franchetella sp.

Franchetella gongrijpii

Franchetella anibifolia

Não identificada

Eremoluma sagotiana

Franchetella tarapotensis

Urbanella procera

Eremoluma purusiana

Eremoluma purusiana 


\section{PENNINGTON}

KUKACHKA

cont. Pouteria seção Franchetella
P. platyphylla
$P$. vernicosa
P. fulva
P. cladantha
$P$. jariensis
$P$. williamii
P. trilocularis
$P$. engleri
P. anomala

P. elegans

P. cuspidata subsp. cuspidata

P. cuspidata subsp. robusta

P. cuspidata subsp. dura

P. gabrielensis

P. ambelaniifolia

P. oblanceolata

P. oppositifolia

$P$. laevigata

P. macrophylla

$P$. rodriguesiana

P. campechiana

$P$. venosa subsp. amazonica

$P$. trigonosperma

P. glomerata subsp. glomerata

P. glomerata subsp. stylosa

P. macrocarpa

$P$. filipes

$P$. euryphylla

$P$. cicatricata

$P$. maguirei

P. stipitata
Franchetella platyphylla

Franchetella sp.

Franchetella sp.

Não identificada

Não identificada

Pouteria obidensis

Eremoluma williamii

P. trilocularis

Micropholis sp.

Nemaluma engleri

Chrysophyllum anomalum

Seção Oxythece

Neoxythece crassifolia

Neoxythece elegans

Neoxythece crassifolia

Neoxythece amazonica

Neoxythece dura

Neoxythece dura

Neoxythece guianensis

Neoxythece robusta

Neoxythece amazonica

Neoxythece dura

Neoxythece schulzii

Neoxythece gabrielensis

Pseudoxythece ambelaniifolia

Seção Oligotheca

Não identificada

Syzygiopsis oppositifolia

Elaeoluma glabrescens

Seção Rivicoa

Richardella macrophylla

Richardella rodriguesiana

Dipholis salicifolia

Seção Antholucuma

Richardella macrocarpa Richardella trigonosperma

Seção Pouteria
Labatia glomerata

Pouteria caimito

Richardella macrophylla Labatia stylosa

Franchetella sp.

Labatia cuprea

Labatia macrocarpa

Richaedella macrophylla

Sem identificação

Labatia euryphylla

Sem identificação

Sem identificação

Labatia parviflora 


\section{PENNINGTON}

KUKACHKA

cont. Pouteria seção Pouteria

P. plicata

P. franciscana

P. gomphiifolia

P. pariry

$P$. guianensis

P. caimito

P. torta subsp. torta

$P$. torta subsp. tuberculata

$P$. torta subsp. glabra

P. hispida

Seção Aneulucuma

P. sapota

Seção Aneulucuma

P. procera

$P$. ephedrantha

P. sclerocarpa

P. krukovii

Seção Gayella

$P$. eugeniifolia

Myrtiluma eugeniaefolia

$P$. decussata

Barylucuma decussata

C. oliviforme subsp. oliviforme

Chrysophyllum

Calocarpum mammosum Urbanella excelsa Urbanella ephedrantha

P. sclerocarpa

P. krukovii

C. argenteum subsp. panamense

Chrysophyllum oliviforme

C. cainito

C. marginatum subsp. marginatum

C. sanguinolentum subsp. spurium

Chrysophyllum panamense

Chrysophyllum cainito

C. sanguinolentum subsp. balata

Chrysophyllum marginatum
Ragala ulei
Ragala sanguinolenta

Ragala ulei

C. ucuquirana-branca

Ragala ulei

C. cuneifolium

C. prieurii

C. lucentifolium subsp. pachycarpum

C. venezuelanense

Prieurella cuneifolia

Prieurella prieurii

Bumelia obtusifolia Gambeya excelsa

A mesma dificuldade que Pennington encontrou para definir grupos, utilizando as características morfológicas disponíveis, Kukachka encontrou com relação às características anatômicas, ou seja, estas ocorrem em vários, mas não em todos os membros de um grupo. Por 
isso estes gêneros foram caracterizados por Kukachka por meio da combinação das características anatômicas do lenho.

\section{Justificativa}

O interesse para a realização deste trabalho está relacionado a uma série de fatores dentre os quais:

- a importância econômica das madeiras da família Sapotaceae no Brasil;

- a alteração significativa na estrutura e circunscrição de Sideroxylon, Pouteria, Chrysophyllum realizadas por Pennington (1990, 1991);

- a importância e dependência da identificação dos gêneros desta família pelo método da anatomia da madeira e

- a permissão em acessar o material cuja observação anatômica da madeira foi realizada por Kukachka (1978 a 1982) e a ultima revisão taxonômica realizada por Pennington (1990, 1991).

\section{Objetivo}

O objetivo deste trabalho é verificar se a anatomia da madeira corrobora a classificação proposta por Pennington em 1990. Objetivos secundários visam sugerir características anatômicas de valor diagnóstico e de significância estatística, buscando contribuir com estudos futuros no agrupamento das espécies brasileiras associadas com as africanas e asiáticas da família.

\section{Material e métodos}

\subsection{Seleção das espécies para estudo anatômico do lenho.}

As espécies selecionadas com base no cruzamento do material estudado por Kukachka (1978-1982) e por Pennington (1990) são listadas a seguir.

\section{Tribo Mimusopeae}

Manilkara (oito espécies, 16 espécimes)

M bidentata subsp. bidentata (A. de Candolle) Chevalier: Pittier, H. 11 848, Venezuela, SJRw 7945;

Williams, LI. 11860, Venezuela, F, MADw 32 888; Williams, LI. 2260, Peru, SJRw 17853. 
M bidentata subsp. surinamensis (A. de Candolle) (Miquel) Pennington, comb. et start. nov.: Krukoff, B. A. 8628, Brasil, NY, MADw 32 852; Krukoff, B. A. 8691, Brasil, NY, MADw 32 851; Wurdack, J. J. \& Adderley, L. S. 42737, Venezuela, NY, MADw 22 363. M chicle (Pittier) Gilly: Kluge, H. C. 55, Panamá, SJRw 7345. M. huberi (Duke) Chevalier: Barbour, P. J. 1052, Panama, SJRw 43 470; Black, G. A. 47-963, SJRw 45 799; Fróes, R. L. 834, Brasil, Aw 27 536. M inundata (Duke) Duke: Krukoff, B. A. 4745, Brasil, NY, MADw 18 543; Krukoff, B. A. 5496, Brasil, NY, MADw 18711 . M. longifolia (A. de Candolle) Dubard: Fróes, R. L. 1080, Brasil Aw 28019. M. maxima Pennington, sp.nov.: Fróes: R. L. 2000, Brasil, Aw 28 024. M. venezuelana (A. Richard) Pennington: Scarff, 18E, SJRw 35 359. M. zapota (Linnaeus) van Royen: Williams, LI. 8260, México, SJRw 34543.

\section{Tribo Sideroxyleae}

Sideroxylon (sete espécies, 13 espécimes)

S. celastrinum (Kunth) Pennington, comb. nov.:Dugand, A. 231, Colômbia, SJRw 22 520; Pittier, H. 4988, Panamá, F, MADw 5817. S. cubense (Grisebach) Pennington, comb.nov.: Bucher 175, Cuba, SJRw 19300. S. jubilla (Ekman ex Urban) Pennington, comb.nov.: Bucher 173, Cuba, SJRw 19298. S. obovatum Lamarck: Curran, H. M. \& Haman, M. 158, Curaçao, SJRw 2137; Curran, H. M. \& Haman, M. 410, Venezuela, SJRw 2785; Miller, G. 1631, Porto Rico, US, MADw 20 858.S. obtusifolium subsp. buxifolium (Roemer\& Schultes) Pennington comb.nov.: Pittier, H. 12 432, Venezuela, SJRw 11 067. S. persimile subsp. Persimile (Hemsley) Pennington: Dugand, A. 508, Colômbia, SJRw 27 080; Kluge, H. C. 12, Panamá, SJRw 7126. S. salicifolium (Linnaeus) Lamarck: Caldwell, D. H. 8786, Flórida, US, MADw 4155, Eggers, H. F. A. von 4106, Bahamas, F\& NY\&US, MADw 9708; Jack, J. G. 5675, Cuba.

Diploon (uma espécie, 1 espécime)

D. cuspidatum (Hoehne) Cronsquist : Hoehne, F. C., 28 358, Brasil, SJRw 23810.

\section{Tribo Chrysophyleae}

Micropholis (11 espécies, 26 espécimes)

M. crassipedicelata (Martius \& Eichler) Pierre: Fróes, R. L.1067, Brasil, Aw 28 001. M. crotonoides (Pierre): Pierre in Pierre \& Urban Cuatrecasas, J. 16 317, Colômbia, SJRw 43 024. M. cylindrocarpa (Poeppig) Pierre: Krukoff B. A. 8355, Brasil, NY, MADw 14 835; Williams, LI. 2995, Peru, SJRw 
18 085. M. egensis (A. Candolle): Pierre in Pierre \& UrbanKrukoff, B. A. 6470, Brasil, NY, MADw 12 511; Lanjouw, J. \& Lindeman, J. C. 2555, Suriname, U , MADw 32 917; Williams, LI. 4903, Peru, F, MADw 16 557. M. gardneriana (A. de Candolle) Pierre: Oliveira, E. 1674, Brasil, MGw 1674. M. guyanensis subsp. duckeana (A. de Candolle) Pierre (Baehni) Pennington, comb.et stat. nov.:Fróes, R. L. 306, Brasil, Aw 27 451; Fróes, R. L. 72, Brasil, Aw 27 357; Fróes, R. L. 73, Brasil. M. guyanensis subsp. guyanensis (A. de Candolle): Pierre Smith, A. C. 2734, Guiana, SJRw 35 684; Wurdack, J. J. \& Adderley, L. S. 43 487, Venezuela, SJRw 54 350; Krukoff, B. A. 6787, Brasil, SJRw 36 872; Williams, LI 3198, Peru, SJRw 18 142. M. madeirensis (Baehni) Aubréville: Fróes, R. L.301, Brasil, SJRw 36 820; Krukoff, B.A. 6813, Brasil, SJRw 36895. M. mensalis (Baehni) Aubréville: Maguire, B. 24 310, Suriname, NY, MADw 11 981; Maguire, B. 24 452, Suriname, NY, MADw 11 999. M. porphyrocarpa (Baehni) Monachino Krukoff, B. A. 6683, Brasil, SJRw 36 820; Smith, A. C. 2627, SJRw 35 638. M. splendens Gilly ex Aubréville: Fróes, R. L.447, Brasil. M. venulosa (Martius \& Eichler) Pierre: Fróes, R. L.360, Brasil, Aw 27 487; Fróes, R. L. 455, Brasil, Aw 27 509; Krukoff, B. A. 8509, Brasil, NY, MADw 17 073. M. williamii Aubréville \& Pellegrin: Fróes, R. L.234, Brasil.

Chromolucuma (uma espécie, 1 espécime)

C. rubriflora Ducke:Fróes, R. L.370, Brasil.

Sarcaulus (duas espécies, cinco espécimes)

S. brasiliensis subsp. brasiliensis (A. de Candolle) Eyma: Krukoff, B.A. 8347, Brasil, MADw 32035 Krukoff, B.A. 6179, Brasil, NY, MADw 12 338. S. vestitus (Baehni) Pennington,comb.nov.: Krukoff, B.A. 4743, Brasil, NY, MADw 9826; Krukoff, B.A. 5013, Brasil, NY, MADw 32 858; Prance, G. T. et al, 13689 , BWCW 28546.

Elaeoluma (uma espécie, duas espécimes)

E. glabrescens (Martius \& Eichler) Aubréville: Fróes, R. L.388, Brasil, A 27 492: Santos, M. R. 201, MGw 1632.

Ecclinusa (duas espécies, cinco espécimes)

E. guianensis Eyma: Pulle, A. 397, Suriname, U, MADw 32 979; Pires, J. M. 51 781, Brasil, U, MADw 21 474. E. lanceolata (Martius \& Eichler) Pierre: Fróes, R. L. 84, Brasil; Fróes, R. L. 200, Brasil, Aw 27 396; Fróes, R. L. 230, Brasil, Aw 27412. 
Pradosia (seis espécies, 10 espécimes)

P. atroviolaceae Ducke: Fróes, R. L. 85, Brasil, Aw 27 366; Krukoff, B. A. 5410, Brasil, NY, MADw 19 054. P. cochlearia subsp. praealta (Lecomte) Pennington comb. nov.: Ducke, A. 825, Brasil, SJRw 32 652. P. colombiana (Standley) Pennington ex T. Ayers \& D. Boufflord: Dugand, A. 703, Colombia, SJRw 28 526. P. cuatrecasii (Aubréville) Pennington, comb. nov.: Cuatrecasas, J. 16 560, Colombia, SJRw 43 056. P. montana Pennington, sp. nov.: Little, E. L. Jr. 6715, Ecuador, MAD, MADw 10 439. P. schomburgkiana subsp. schomburgkiana (A. de Candolle) Cronquist : Davidse, G. et al 17 792; Ducke, A. 264, Brasil, SJRw 32 640; Maguire, B \& Politi, W 27 865, Venezuela, SJRw 52 105; Maguire, B, 24 309, Suriname, SJRw 44116.

Pouteria (54 espécies, 111 espécimes)

(Seção Franchetella) P. anomala (Pires) Pennington, comb. nov.: Plowman, T. et al., 9501. P. bilocularis (Winkler) Baehni: Krukoff, B. A 7049, Brasil, NY, MADw 12 797; Krukoff, B. A 8663, Brasil, NY, MADw 32 235. P. cladantha Sandwith: Krukoff, B. A. 8316, Brasil, MADw 32 026. P. coriacea (Pierre) Pierre: Cowan, R. S. \& Lindeman, J. C. 39 094, Suriname, NY, U, MADw 32 940. P. egregia Sandwith: Breteler, F. J. 5004, Venezuela, SJRw 55 663; Wurdack, J. J. \& Monachino, J. V. 39 693, Venezuela, SJRw 50 080; Pires, J. M. et al., 51287, Brasil, MADw 21 298; Schulz, J. P. 7326, Suriname, MADw 32 943. P. fulva Pennington, sp. nov.: Krukoff, B. A. 8882, Brasil, NY, MADw 32 308. P. gongrijpii Eyma: Nascimento, O. C., 323, Brasil, MGw 1356; Schulz, J. P. 7449, Suriname, U, MADw 32 948; Stahel, G. 233, Suriname, SJRw 41280. P. jariensis Pires \& Pennington, sp. nov.: Krukoff, B. A. 1389, Brasil, NY, MADw 32 864. P. lucumifolia (Reissik ex Maximowicz) Pennington, comb. nov.: Wurdack, J. J. \& Adderley, L. S. 43 111, Venezuela, SJRw 54 101. P. platyphylla (A.C.Smith) Baehni: Fróes, R. L. 166, Brasil. P. putamen-ovi Pennington, sp.nov.: Krukoff, B. A 1346, Brasil, NY, MADw 32 874. P. ramiflora (Martius) Radlkofer: Krukoff, B. Aw 11252, Bolivia, NY, MADw 33 994; Plowman, T. et al., 9178. P. reticulata subsp. reticulate (Engler) Eyma: Krukoff, B. A 1447, Brasil, NY, MADw 32 866; Krukoff, B. A 5009, Brasil, NY, MADw; Krukoff, B. A 6568, Brasil 9852, NY, MADw 12 532; Plowman, T. et al., 9457. P. retinervis Pennington, sp. nov.: Fróes, R. L. 38, Brasil. P. rostrata (Huber) Baehni. Fróes, R. L. 886, Brasil; Krukoff, B. A. 5318, Brasil, NY, MADw 17 397; Krukoff, B. A. 5701, Brasil, NY, MADw 17398. P. sagotiana (Baillon) Eyma: Lanjouw, J. \& Lindeman, J. C. 2651, Suriname, U, MADw 32 921.P. trilocularis Cronquist: Krukoff, B. A. 5283, Brasil, NY, MADw 19 022; Krukoff, B. A. 5338, Brasil, NY, MADw 19 040, Krukoff, B. A. 5435, Brasil, NY, MADw 18 697. P. vernicosa Pennington, sp. nov.: 
Krukoff, B. A. 8192, Brasil, NY, MADw 31 831. P. williamii (Aubréville \& Pellegrin) Pennington, comb. nov.: Fróes, R. L. 576, Brasil; Rodrigues, W. \& Loureiro, A., 7180, BCTw 11 647. (Seção Oxythece) P. ambelaniifolia (Sandwith) Pennington: Sandwith, N. Y. 372, Guiana; Forest Dep. 1196, SJRw 32880 e SJRw 43 581, K, MADw 4730. P. cuspidata subsp. cuspidate (A. de Candolle) Baehni: Fróes, R. L. 95, Brasil, Aw 27 369; Fróes, R. L. 214, Brasil, Aw 27 405; Fróes, R. L. 289, Brasil, Aw 27 442. P. cuspidata subsp. dura (A. de Candolle) Baehni (Eyma): Fróes, R. L. 83, Brasil, Aw 27 364; Fróes, R. L. 184, Brasil, Aw 27 388; Schulz, J. P. 7327, Suriname, U, MADw 32 944. P. cuspidata subsp. robusta (A.de Candolle) Baehni (Martius \& Eichler) Pennington: Fróes, R. L. 312, Brasil, Aw 27 455; Fróes, R. L. 354, Brasil, Aw 27 485; Schulz, J. P. 7425, Suriname, U, MADw 32 946. P. elegans (A. de Candolle) Baehni: Fróes, R. L. 151, Brasil, Aw 27 377; Fróes, R. L. 263, Brasil, Aw 27 429; Wurdack, J. J. \& Adderley, L. S. 43 203, Venezuela, SJRw 54 203. P. gabrielensis (Gilly ex Aubréville) Pennington: Fróes, R. L. 397, Brasil, Aw 27 493; Maguire, B. et al. 41 874, Venezuela, SJRw 52 427. (Seção Oligotheca) P. laevigata (Martius) Radlkofer: Fróes, R. L. 257, Brasil, A 27 425; Fróes, R. L. 509, Brasil, Aw 27 514. P. oblanceolata Pires: Prance, G. T. et al, 11684 , BWCw 28 464. P. oppositifolia (Duke) Baehni: Capucho, D. 378, Brasil, MAD, MADw 23 675. (Seção Rivicoa) P. campechiana (Kunth in Humboldt, Bonpland \& Kunth) Baehni: Lundell, C. L., 6, SJRw 19 829. P. macrophylla (Lamarck) Eyma: Capucho, D. 428, Brasil, MAD, MADw 23 687, U, MADw 21752; Krukoff, B. A. 5711, Brasil, NY, MADw 18765. P. rodriguesiana Pires \& Pennington: Rosa, N. A. 1103, Brasil, MGw 730; Rosa, N. A. 1181, Brasil. (Seção Antholucuma) P. trigonosperma Eyma: Lindeman, J. C. 4151, Suriname, U, MADw 32 934. P. venosa subsp. amazonica (Martius) Baehni Pennington, subsp. nov.: Capucho, D. 409, Brasil, MAD, MADw 23683. (Seção Pouteria) P. caimito (Ruiz \& Pavón) Radlkofer: Fróes, R. L. 408, Brasil; Krukoff, B. A. 1322, Brasil, NY, MADw 32 875; Smith, A. C. 3245, Guiana, SJRw 35 879; Williams, LI. 14300 , Venezuela, F, MADw 32 900. P. cicatricata Pennington, sp. nov.: Fróes, R. L. 67, Brasil, Krukoff, B. A. 6793, Brasil. P. euryphylla (Standley) Baehni: Cooper, G. P. 611, Panamá, SJRw 12 244. P. filipes Eyma: Oliveira, E. 4465; Oliveira, E. 4504. P. franciscana: Krukoff, B. A. 6211, Brasil, NY, MADw 12 354. P. glomerata subsp. glomerata (Miquel) Radlkofer: Fróes, R. L. 195, Brasil, A 27395; Krukoff, B. A. 5106, Brasil, NY, MADw 32 863;Oliveira, E. 4453. P. glomerata subsp. stylosa (Miquel) Radlkofer (Pierre) Pennignton: Cooper, G. P. 509, Panamá, SJRw 12 128; Plowman, T. et al., 9454; Rodrigues, W \& Lima, J 2532, Brasil, INPA 943. P. gomphiifolia (Martius) Radlkofer: Fróes, R. L. 191, Brasil; Fróes, R. L. 258, Brasil; Fróes, R. L. 269, Brasil. P. guianensis Aublet: Cuatrecasas, J. 16 396, Colômbia, SJRw 43 036; Fróes, R. L. 152, Brasil; Fróes, R. L. 407. P. hispida Eyma: Fróes, R. L. 185, Brasil; Krukoff, B. A. 6344, Brasil, NY, MADw 12 427; Krukoff, B. A. 8649, Brasil, MADw 
32 221. P. macrocarpa (Huber) Duke: Capucho, D. 405, Brasil, MAD, MADw 23 680. P. maguirei (Aubréville) Pennington: Fróes, R. L. 454, Brasil. P. pariry (Ducke) Baehni: Capucho, D. 431, Brasil, F, MADw 20907. P. plicata Pennington: Fróes, R. L. 150, Brasil; Fróes, R. L. 226, Brasil, Aw 27 410; Krukoff, B. A. 5602, Brasil, NY, MADw 18 732; Krukoff, B. A. 6632, Brasil, NY, MADw 12 580. P. stipitata Cronquist: Fróes, R. L. 204, Brasil, Aw 27 399. P. torta subsp. glabra (Martius) Radlkofer Pennington: Fróes, R. L. 192, Brasil; Fróes, R. L. 207, Brasil; Williams, LI. 4951, Peru, F, MADw 16 351. P. torta subsp. torta (Martius) Radlkofer: Krukoff, B. A. 1201, Brasil, NY, MADw 32 871. P. torta subsp. tuberculata (Martius) Radlkofer (Sleumer) Pennington: Cooper, G. P. 499, Panamá, US, MADw 10 166. (Seção Aneulucuma) P. ephedrantha (A. C. Smith) Pennington Krukoff, B. A. 5163, Brasil, NY, MADw 18 635; Krukoff, B. A. 5422, Brasil, NY, MADw 19 060. P. rukovii (A. C. Smith) Baehni: Krukoff, B. A., 5700, Brasil. P. procera (Martius) Pennignton: Krukoff, B. A. 5177, Brasil, NY, MADw 18 643; Krukoff, B. A. 5397, Brasil, NY, MADw 18 687; Krukoff, B. A. 5534, Brasil, NY, MADw 18 717. P. sapota (Jacquin) H. E. Moore \& Stearn: Englesing, F. C. 85, Nicarágua, SJRw 12 414; Williams, LI 8321, México, F, MADw 16 149; Williams, LI 9272, México, F, MADw 16 148. P. sclerocarpa (Pittier) Cronquist: Pittier, H., 4357, F, MADw 5804. (Seção Gayella) P. decussata (Ducke) Baehni: Silva, N. T., 3176, IAN 135 031. P. eugeniifolia (Pierre) Baehni: Maguire, B. 24 739, Suriname, NY, MADw 12 101; Maguire, B \& Politi, W 28 715, Venezuela, SJRw 52 262; Maguire, B \& Politi, W 28 742, Venezuela, SJRw 52273.

Chrysophyllum (15 espécies, 33 espécimes)

C. argenteum subsp. panamense Jacquin (Pittier) Pennington: Cooper, G. P. 353, Panamá, US, MADw 32 898. C. cainito Linnaeus: Kluge, H. C. 49, Panamá, SJRw 7248. C. cuneifolium (Rudge) A. de Candolle: Lanjouw, J. \& Lindeman, J. C. 2977, Suriname, U, MADw 32924 / Uw 1981; Maguire, B. 24 687, Suriname, NY, MADw 12 071. C. lucentifolium subsp. pachycarpum Pires \& Pennington: Little, E. L. Jr. 6612, Equador, US, MADw 10427. SJRw 40 978. C. marginatum subsp. marginatum (Hooker \& Arnott) Radlkofer: Curran, H. M. 713, Argentina, SJRw 1719. C. oliviforme subsp. oliviforme Linnaeus: Caldwell, D. H. 8731, Flórida, NY, MADw 1283, SJRw 49 259. C. prieurii A. de Candolle: Ducke, A. 813, Brasil, SJRw 44 304; Pires, J. M. 51794, Brasil, NY, MADw 21 487; Williams, LI. 14 550, Venezuela, SJRw 41 625. C. sanguinolentum subsp. balata (Pierre) Baehni (Ducke) Pennington: Smith, A. C. 2966, Guiana, SJRw 35 758; Fróes, R. L. 419, Brasil, Aw 27 500; Williams, LI. 911, Peru, SJRw 17 473. C. sanguinolentum subsp. spurium (Pierre) Baehni (Ducke) Pennington: Krukoff, B. A. 6800, Brasil, SJRw 36 883; Williams, LI. 929, Peru, SJRw 17 488. C. ucuquirana-branca (Aubréville \& Pellegrin) Pennington: Fróes, R. L. 878, Brasil, Aw 27 540. C. 
venezuelanense (Pierre) Pennington: Williams, LI, 10 062, Venezuela, F, MADw 9854; Capucho, D. 567, Brasil, F, MADw 20501.

Os indivíduos escolhidos estão representados nas seguintes coleções:

- Aw - Bailey-Wetmore Laboratory of Plant Anatomy and Morphology, Harvard University Herbaria - Cambridge Masschusets, Estados Unidos da América

- BCTw - Instituto de Pesquisas Tecnológicas do Estado de São Paulo S.A. - IPT São Paulo, Brasil

- BWCw - Harry Phillip Brown Memorial Wood Collection, College of Environmental Science and Forestry, State University of New York - New York, Estados Unidos da América

- IAN - Embrapa Amazônia Oriental - Belém, Brasil

- MADw, MAD-SJRw - U. S. Forest Products Laboratory - Madison, Estados Unidos da América

- MGw - Museu Paraense Emílio Goeldi - Belém, Brasil

- Uw - Nationaal Herbarium Nederland - Utrecht, Holanda

\subsection{Seleção das características anatômicas.}

O levantamento completo dos dados anatômicos foi obtido para o aproveitamento, não apenas neste trabalho, mas também, para alimentar os bancos de dados que estão sendo formados para as coleções de madeira Dr. Calvino Mainieri (BCTw) e Nanuza Luiza de Menezes (SPFw).

As características anatômicas consideradas neste trabalho seguiram a terminologia adotada pela lista de características microscópicas para identificação de madeiras (IAWA Comitee, 1989).

Para as características quantitativas, foi realizada a biometria dos seguintes parâmetros:

- diâmetro e comprimento dos elementos de vaso;

- tamanho da pontoação intervascular;

- altura dos raios;

- largura dos raios e

- freqüência de vasos e raios.

Foram realizadas 30 medições para estes parâmetros, número calculado a partir da seguinte fórmula sugerida por Costa Neto (1977): 
$\mathrm{t}=\mathrm{t}$ de student

S=desvio padrão

E=erro permissível

$$
N=\frac{\left(t^{2} \times S^{2}\right)}{E^{2}}
$$

As mensurações foram realizadas em cada indivíduo, e, para todas as características quantitativas, foram efetuados cálculos de média aritmética (X) e desvio padrão (s). Nas descrições e nos quadros, foram considerados os valores mínimo, médio, máximo, seguindo o desvio padrão.

A biometria foi realizada com o microscópio acoplado a câmera fotográfica digital Zeiss KS100. A estatística dos dados biométricos foi realizada utilizando-se análise multivariada por meio do software Jump (versão 5.0.1).

\subsection{Preparação do material para estudo anatômico.}

Com relação aos espécimes da coleção de Madison, já existiam lâminas histológicas, que foram remetidas ao Brasil, contendo secções transversais, tangenciais e radiais. Entretanto, aproximadamente 460 lâminas precisaram ser remontadas, uma vez que a resina utilizada na montagem sofreu cristalização, o que impossibilitava a observação. A remontagem das lâminas seguiu, primeiramente, com o descolamento da lâmina, lamínula e das secções, cada conjunto foi mergulhado em água destilada a aproximadamente $70^{\circ} \mathrm{C}$. Em seguida, a resina foi removida das secções seguindo a série etílica e mergulhando-as em acetato de n-butila. As secções naturais foram montadas novamente em resina sintética e as anteriormente coradas com safranina foram gradualmente hidratadas até etanol $50 \%$ e recoloridas com o mesmo corante. Após este procedimento seguiu-se o mesmo procedimento anterior de desidratação e remontagem.

Foram confeccionadas lâminas apenas para as amostras da coleção Dr. Calvino Mainieri (BCTw), que não estavam representadas no laminário oficial da instituição. Cubos de aproximadamente $1 \mathrm{~cm}^{2}$ foram removidos das amostras da coleção e amolecidos, por fervura em água e glicerina na proporção de 1:1. Posteriormente, secções transversais, tangencias e radiais foram obtidas em micrótomo de deslize com navalha tipo $\mathrm{C}$, seguindo a metodologia descrita em Gerlach (1984), clarificadas com água sanitária, coradas com safranina $1 \%$ em etanol 50\%, desidratadas e montadas em resina sintética. 


\section{Resultados}

\subsection{Levantamento das características anatômicas}

\subsubsection{Gênero Manilkara}

CAMADAS DE CRESCIMENTO

Com exceção de Manilkara zapota, onde não foram observadas camadas de crescimento, as outras espécies as apresentam demarcadas por três marcadores de crescimento (Tabela 2): pelo achatamento radial das fibras, presente na maioria das espécies, exceto em $M$. longifolia; por uma linha de parênquima axial com células achatadas radialmente, constituindo o parênquima marginal, exceto em M. maxima; e pela presença de vasos de pequeno diâmetro tangenciando a camada de crescimento, exceto em M. huberi (Figs. 1-4).

\section{VASOS}

A porosidade é difusa em todos os espécimes analisados. No gênero, o arranjo dos vasos é predominantemente radial e/ou diagonal (Fig. 3), sendo que 0 arranjo difuso foi observado em um espécime de Manilkara bidentata subsp. bidentata, de Manilkara bidentata subsp. surinamensis e de M. inundata, além dos três espécimes de M. huberi (Fig. 4). Os vasos são predominantemente múltiplos de dois e três, podendo ocorrer esporadicamente vasos solitários e múltiplos de quatro (Fig. 5). Apresentam placa de perfuração simples (Fig. 7), entretanto em M. zapota foi observada a ocorrência de vestígios de barras presentes nas placas múltiplas (Fig. 8). Quanto às pontoações intervasculares, tem-se a média para o diâmetro horizontal de $6 \mu \mathrm{m}$, sendo classificada como pequena; a variação da média entre as espécies se estabelece entre $3 \mu \mathrm{m}$, observada em $M$. bidentata subsp. bidentata, e $7 \mu \mathrm{m}$, observada em $M$. maxima e $M$. venezuelana. A média, para 0 gênero, do diâmetro tangencial do vaso, é de $75 \mu \mathrm{m}$; a variação do valor médio entre as espécies ocorre entre $50 \mu \mathrm{m}$ e $160 \mu \mathrm{m}$, entretanto apenas este valor mais elevado (160 $\mu \mathrm{m})$ é observado no

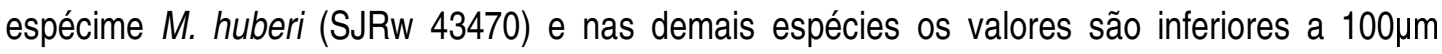
(Figs.9-10). Em geral, as freqüências médias estão nos limites da categoria de 5 a 20 vasos $/ \mathrm{mm}^{2}$ (IAWA Committee 1989), apresentando média geral de $14 \mathrm{vasos} / \mathrm{mm}^{2}$, sendo que os menores valores são observados em $M$. huberi (5-6 vasos $/ \mathrm{mm}^{2}$ ). 0 comprimento médio do elemento de vaso considerando todas as espécies analisadas é de $569 \mu \mathrm{m}$, variando de $404 \mu \mathrm{m}$ a $732 \mu \mathrm{m}$, se inserindo na categoria de $350 \mu \mathrm{m}$ a $800 \mu \mathrm{m}$, estabelecida pela IAWA Committee (1989). Foi observada a presença de tilos não esclerificados em todas as espécies, exceto em M. maxima e M. zapota nas 
quais não se observou sua presença (Fig. 5). Em M. valenzuelana são observados grandes cristais no interior dos tilos.

\section{TRAQUEÍDES VASICÊNTRICAS}

A visualização destes elementos é muito difícil, entretanto sua presença foi diagnosticada em secções longitudinais, principalmente no longitudinal radial, sempre adjacente aos vasos, em disposição ondulada.

\section{$\underline{\text { FIBRAS }}$}

Apresentam pontoações com aréolas diminutas a pontoações simples e paredes muito espessas (Fig. 2).

\section{PARÊNQUIMA AXIAL}

O parênquima ocorre principalmente em forma de linhas, que variam de uma a três células de largura, mas também com mais de três células de largura em M. bidentata subsp. surinamensis. Em M. zapota, observa-se o parênquima difuso em agregados, tendendo a formar linhas com uma célula de largura (Figs. 1-6). É seriado com duas a oito células por série.

$\underline{\text { RAIOS }}$

Os raios são predominantemente uni a bisseriados no gênero, sendo menos comum o tecido radial composto por uma a três células de largura, como em $M$. bidentata subsp. bidentata (MADw 32 888), M. chicle, M. inundata (MADw 18 542) e em M. huberi (Aw 27536, SJRw 43 470) (Figs. 11-12). Têm uma altura média de $323 \mu \mathrm{m}$, variando de 266 a $435 \mu \mathrm{m}$. Têm uma freqüência média de 12 raios $/ \mathrm{mm}$, sendo a variação entre 10 e 15 raios $/ \mathrm{mm}$. O corpo dos raios está composto por células procumbentes e as margens por duas a quatro camadas de células quadradas e/ou eretas (Fig. 13). Não foi observada a presença de células perfuradas de raio nas espécies analisadas. Células disjuntivas radiais estão presentes, apresentando longas projeções em todas as espécies analisadas (Fig. 14). Há uma variação no tipo e localização das pontoações raiovasculares no gênero. As pontoações arredondadas prevalecem nas células eretas, quadradas e procumbentes do raio. Por outro lado, as pontoações escalariformes somente são observavas nas células eretas e quadradas e, nessas células são observadas em menor freqüência as pontoações reticuladas. Nas células procumbentes predominam as pontoações semelhantes às intervasculares. 
Também são observadas, em menor freqüência, pontoações unilateralmente compostas tanto nas células quadradas quanto nas procumbentes (Figs. 15-17).

\section{INCLUSÕES MINERAIS}

São observados cristais prismáticos em células subdivididas do parênquima axial, na maioria das espécies analisadas, exceto em M. bidentata subsp. bidentata (SJRw 7945, SJRw 17853) e M. huberi (SJRw 43470). Cristais prismáticos em células eretas e quadradas subdivididas do raio são observados em em $M$. bidentata subsp. bidentata e em M. chicle. Corpos silicosos, presentes nos três tipos de células radiais, são notados apenas no espécime $M$. huberi (SJRw 43470 ), no qual não foi observada a presença de cristais prismáticos nem no parênquima axial nem no radial (Figs. 18-21).

\subsubsection{Gênero Sideroxylon}

As características anatômicas qualitativas e quantitativas das espécies de Sideroxylon analisadas foram condensadas na tabela 3. A lista de características microscópicas da IAWA (IAWA Committee 1989) foi utilizada como parâmetro para as observações. Os resultados foram apresentados de forma descritiva para cada característica analisada. As características que não estão especificadas não se aplicam ou não ocorrem no grupo.

\section{CAMADAS DE CRESCIMENTO}

As camadas de crescimento podem estar presentes ou ausentes. Quando presentes são demarcadas pela presença do parênquima axial achatado radialmente, constituindo o parênquima marginal. Adjacente a estas regiões, ou seja, no limite das camadas de crescimento, também foi observada a ocorrência de vasos de menor diâmetro. Eventualmente foram observadas fibras achatadas, também no limite dessas camadas. A ocorrência de zonas fibrosas foi observada, esporadicamente, apenas nas espécies S. obovatum e S. jubilla (Figs. 22-24).

\section{$\underline{\text { VASOS }}$}

Em todos os espécimes analisados, a porosidade é difusa. Arranjo - No gênero Sideroxylon predomina o arranjo radial e/ou diagonal tendendo ao arranjo dendrítico (Figs. 24-25). $\mathrm{Na}$ espécie Sideroxylon salicifolium a distribuição difusa dos vasos foi predominante. (Fig. 22). Agrupamento - Vasos múltiplos de dois e três são predominantes no gênero Sideroxylon, 
ocorrendo concomitantemente com vasos solitários e múltiplos de quatro ou mais (Fig. 22). Placa de perfuração - Em todos os indivíduos do gênero foi observada placa de perfuração simples, no especime Sideroxylon persimile subsp. persimile (SJRw 7126) foi diagnosticado vestigio de barra de placa de perfuração múltipla (Fig. 26). Pontoação intervascular - A média para 0 diâmetro horizontal da câmara da pontoação intervascular foi de $4 \mu \mathrm{m}$ no gênero Sideroxylon, sendo classificada como pequena de acordo com as categorias estabelecidas pela IAWA (IAWA Committee 1989). Pontoação raio-vascular - As pontoações arredondadas com aréolas muito reduzidas a aparentemente simples ocorreram nas células eretas, quadradas e procumbentes $e$ além deste tipo também foram observadas pontoações alongadas horizontalmente à escalariformes nas células eretas; reticuladas, alongadas horizontalmente à escalariformes, alongadas diagonalmente e unilateralmente compostas nas células quadradas; e pontoações semelhantes às intervasculares e unilateralmente compostas nas células procumbentes (Fig. 27). Diâmetro tangencial médio do lume do vaso - A média para o diâmetro tangencial do lume do vaso foi de

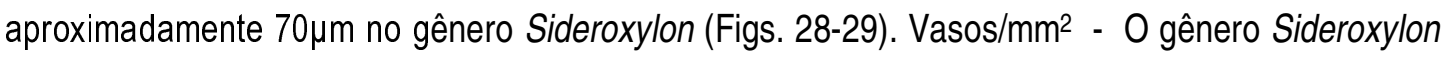
apresentou média geral de 25vasos $/ \mathrm{mm}^{2}$. A espécie Sideroxylon obtusifolium subsp. buxifolium se destacou por apresentar média de 67vasos $/ \mathrm{mm}^{2}$. Comprimento médio do elemento de vaso Devido à ausência de material para preparação de macerado todos os valores foram obtidos na secção tangencial, por isso, não foi possível estabelecer o comprimento de um apêndice ao outro. Desse modo esta característica só poderá ser utilizada para comparação entre os indivíduos analisados unicamente neste trabalho, não sendo parâmetro para discussões com a literatura pesquisada. Todas as médias obtidas a partir das lâminas analisadas variaram de aproximadamente $200 \mu \mathrm{m}$ a $500 \mu \mathrm{m}$ com exceção de Sideroxylon jubilla cuja média foi de $700 \mu \mathrm{m}$. Tilos e depósitos nos vasos - Foi observada a presença de tilos nos vasos das espécies analisadas. A presença não se aplica a todos os vasos em um mesmo espécime, assim como nem todos os indivíduos apresentaram esta característica (Figs. 22 e 35).

\section{TRAQUEÍDES E FIBRAS}

Traqueídes vasicêntricas e vasculares - A visualização destes elementos em secções longitudinais é muito difícil entretanto a presença foi diagnosticada em todas as espécies. Tipo de pontoação das fibras - Apesar das paredes das fibras serem, em geral, muito espessas, foi possível determinar que as fibras possuem pontoações simples e pontoações com aréola diminuta. Espessamento da parede da fibra - As paredes das fibras são muito espessas (Fig. 23). 


\section{PARÊNQUIMA AXIAL}

As linhas podem variar de apenas uma célula de largura (S. salicifolium) (Fig. 22); ou linhas com duas a três células de largura, até linhas com mais de quatro células ( $S$. persimile subsp. persimile) (Fig. 30). Célula do parênquima axial: tipo/comprimento da série - Em Sideroxylon foi diagnosticado parênquima com oito células por série.

$\underline{\text { RAIOS }}$

Raios bisseriados predominam no gênero Sideroxylon e somente em $S$. persimile subsp. persimile e em S. celastrinum os raios possuem mais de três células de largura (Fig. 31-32).

Altura - Nenhum raio apresentou altura superior a $1 \mathrm{~mm}$. A média obtida foi de aproximadamente $300 \mu m$. Composição celular - Esta característica não é facilmente interpretada devido a freqüente ocorrência de raios fusionados. Nas espécies $S$. persimile subsp. persimile, $S$. obovatum, $S$. obtusifolium subsp. buxifolium e $S$. celastrinum, os raios são formados por células procumbentes e duas a quatro células marginais quadradas e/ou eretas. Em S. cubense, S. jubilla e S. salicifolium os raios são formados por células procumbentes e mais de quatro camadas de células quadradas e/ou eretas nas extremidades (Figs. 33-34). Células perfuradas de raio - Foi observada a presença desse tipo celular apenas em um espécime de S. jubilla (SJRw 19298) (Fig. 35). O fato de células perfuradas não terem sido observadas em todo o gênero não significa que elas não estejam presentes, pois costumam ocorrer em baixa freqüência (IAWA Committee 1989). Células do parênquima radial com paredes disjuntivas - Foi observada a presença de células disjuntivas em todas as espécies analisadas diferenciando-se apenas na dimensão das projeções, que foram classificadas como longas e curtas (Fig. 36-37). Raios/mm - Todas as médias obtidas a partir das espécies analisadas se inseriram na categoria 4 a 12 raios $/ \mathrm{mm}$, sendo a média para 0 gênero de 8 raios $/ \mathrm{mm}$.

\section{INCLUSÕES MINERAIS}

Nas espécies $S$. persimile subsp. persimile, S. obovatum, S. obtusifolium subsp. buxifolium e $S$. celastrinum, foi observada a presença de cristais areniformes nas células do parênquima axial e apenas em $S$. obovatum este tipo de cristal foi observado também nas células do raio. Cristais prismáticos e cúbicos ocorreram esporadicamente no raio de $S$. obovatum e cristais estiloidais foram observados no parênquima axial de $S$. obtusifolium subsp. buxifolium (Figs. 38-40). Em $S$. jubilla cristais prismáticos foram observados nas células do parênquima axial e radial e cristais 
areniformes foram vistos nas células procumbentes do raio. Não foi diagnosticada a presença de corpos silicosos em nenhuma célula parenquimática das espécies analisadas.

\subsubsection{Gênero Diploon}

As características anatômicas qualitativas e quantitativas de Diploon cuspidatum foram condensadas na tabela 3. A lista de características microscópicas da IAWA (IAWA Committee 1989) foi utilizada como parâmetro para as observações. Os resultados foram apresentados de forma descritiva para cada característica analisada. As características que não estão especificadas não se aplicam ou não ocorrem no grupo.

\section{CAMADAS DE CRESCIMENTO}

As camadas de crescimento estão presentes e são demarcadas por um achatamento radial das fibras podendo compreender uma faixa com mais de três linhas. Adjacente a estas regiões, ou seja, no limite das camadas de crescimento, também foi observada a ocorrência de uma ou mais linhas de parênquima axial achatadas radialmente, constituindo o parênquima marginal, assim como a presença de vasos de menor diâmetro (Figs. 41-42).

$\underline{\text { VASOS }}$

A porosidade é difusa. Arranjo - No gênero Diploon os vasos estão distribuídos de forma difusa (Fig. 43). Agrupamento - Vasos múltiplos de dois e três são predominantes no gênero Diploon, ocorrendo concomitantemente com vasos solitários (Figs. 41-43). Placa de perfuração Em Diploon foi observada placa de perfuração simples (Fig. 44). Pontoação intervascular - $O$ valor médio para o diâmetro horizontal da câmara da pontoação intervascular foi de aproximadamente $4 \mu \mathrm{m}$ sendo classificada como pequena de acordo com as categorias estabelecidas pela IAWA (IAWA Committee 1989). Pontoação raio-vascular - As pontoações arredondadas com aréolas muito reduzidas a aparentemente simples ocorreram nas células eretas, quadradas e procumbentes. Também foram observadas pontoações alongadas horizontalmente à escalariformes nas células eretas, pontoações alongadas horizontalmente, diagonalmente e verticalmente nas células quadradas e pontoações semelhantes às intervasculares nas células procumbentes (Figs. 45-46). Diâmetro tangencial médio do lume do vaso - A média para o diâmetro tangencial do lume do vaso foi de 50um em Diploon cuspidatum. Vasos $/ \mathrm{mm}^{2}$ - A freqüência de vasos em Diploon assim como em Elaeoluma foi uma das mais baixas observadas em Sapotaceae, com a ocorrência 
média de 3vasos $/ \mathrm{mm}^{2}$. Comprimento médio do elemento de vaso - Devido à ausência de material para preparação de macerado todos os valores foram obtidos na secção tangencial, por isso, não foi possível estabelecer o comprimento de um apêndice ao outro. Desse modo esta característica só poderá ser utilizada para comparação entre os indivíduos analisados unicamente neste trabalho, não sendo parâmetro para discussões com a literatura pesquisada. A média obtida a foi de aproximadamente $300 \mu \mathrm{m}$. Tilos e depósitos nos vasos - Foi observada a presença de tilos comuns (Fig. 41-44).

\section{TRAQUEÍDES E FIBRAS}

A visualização destes elementos em secções longitudinais é muito difícil e não foi observada nesta espécie. Tipo de pontoação das fibras - As fibras possuem pontoações simples e pontoações com aréola diminuta. Espessamento da parede da fibra - As paredes das fibras foram consideradas muito espessas (Fig. 42-43).

\section{PARÊNQUIMA AXIAL}

As linhas possuem de 1 a 3 células de largura (Figs. 41-43). Célula do parênquima axial: tipo/comprimento da série - Em Diploon cuspidatum predomina o parênquima com mais de oito células por série.

\section{$\underline{\text { RAIOS }}$}

Largura do raio - Os raios apresentaram de uma a duas células de largura (Fig. 47). Altura - Nenhum raio apresentou altura superior a $1 \mathrm{~mm}$ e a média foi estabelecida em torno de $300 \mu \mathrm{m}$. Raios de dois tamanhos distintos - Não foi observada a ocorrência de raios de dois tamanhos distintos. Composição celular - Foram observados raios constituídos por um corpo central de células procumbentes e duas a quatro camadas de células marginais quadradas e/ou eretas. A ocorrência de trabéculas nas células do raio foi observada para esta espécie (Fig. 48). Células perfuradas de raio - Foi observada a presença desse tipo celular em Diploon cuspidatum (Fig. 49). Células do parênquima radial com paredes disjuntivas - Foi observada a presença de células disjuntivas com projeções curtas (Fig. 48). Raios/mm - A média obtida a partir dos dois espécimes analisados foi de 17 raios $/ \mathrm{mm}$. 


\section{INCLUSÕES MINERAIS}

No gênero Diploon não foi observado nenhum tipo de cristal tanto nas células do parênquima axial quanto nas do parênquima radial. $O$ tipo de inclusão mineral mais visível foram os corpos silicosos, presente nas células do parênquima radial. No raio, os corpos silicosos foram observados nas células eretas, quadradas e procumbentes (Fig. 48).

\subsubsection{Gênero Micropholis}

As características anatômicas qualitativas e quantitativas das espécies de Micropholis estudadas, que ocorrem no continente americano, foram condensadas na tabela 4. A lista de características microscópicas da IAWA (IAWA Committee 1989) foi utilizada como parâmetro para as observações. Os resultados foram apresentados de forma descritiva para cada característica analisada. As características que não estão especificadas não se aplicam ou não ocorrem no grupo.

\section{CAMADAS DE CRESCIMENTO}

As camadas de crescimento podem estar presentes ou ausentes. Quando presentes são demarcadas por um achatamento radial das fibras podendo compreender uma linha ou uma faixa com mais de três linhas. Nas espécies em que as fibras apresentam paredes pouco espessas foi observado, além do achatamento, um incremento na espessura das paredes na região do lenho tardio. Adjacente a estas regiões, ou seja, no limite das camadas de crescimento, também foi observada a ocorrência do parênquima axial achatado radialmente, constituindo o parênquima marginal, assim como a presença de vasos de menor diâmetro. A ocorrência de zonas fibrosas foi observada esporadicamente. Esta característica pode ou não estar associada com os marcadores descritos anteriormente e foi definida como uma região na qual ocorre a diminuição de linhas do parênquima axial na direção do lenho tardio, resultando em áreas onde predominam fibras e poucos vasos, denominadas zonas fibrosas. (Figs. 50-51).

\section{VASOS}

Em todos os espécimes analisados, a porosidade é difusa. Arranjo - No gênero Micropholis os vasos estão distribuídos predominantemente de forma difusa. Nas espécies $M$. egensis, $M$. mensalis M. cylindrocarpa e M. madeirensis foi observada unicamente uma distribuição radial e/ou diagonal dos vasos (Figs. 52-53). Agrupamento - Vasos múltiplos de dois e três são predominantes no gênero Micropholis, ocorrendo concomitantemente com vasos solitários e eventualmente 
múltiplos de quatro ou mais (Fig. 52). Placa de perfuração - Em todos os indivíduos do gênero foi observada placa de perfuração simples. Pontoação intervascular - A média para o diâmetro horizontal da câmara da pontoação intervascular foi de $4 \mu m$ no gênero Micropholis, sendo classificada como pequena de acordo com as categorias estabelecidas pela IAWA (IAWA Committee 1989). Pontoação raio-vascular - Houve uma ampla variação no tipo e localização das pontoações raio-vasculares no gênero Micropholis. Com exceção das pontoações semelhantes às intervasculares, as demais apresentaram aréolas muito reduzidas a aparentemente simples. Nas células eretas do raio prevaleceram as pontoações alongadas horizontalmente à escalariformes, seguidas pelas pontoações arredondadas com aréolas muito reduzidas a aparentemente simples. Nas células quadradas, houve uma distribuição mais uniforme entre os seguintes tipos de pontoação: arredondadas com aréolas muito reduzidas a aparentemente simples; reticuladas; alongadas diagonalmente com aréolas muito reduzidas a aparentemente simples; alongadas horizontalmente à escalariformes; e unilateralmente compostas. Nas células procumbentes, as pontoações arredondadas e as semelhantes às intervasculares foram predominantes. Também foram observadas, em menor freqüência, pontoações alongadas verticalmente e pontoações unilateralmente compostas (Figs. 54-55). Diâmetro tangencial médio do lume do vaso - A média para 0 diâmetro tangencial do lume do vaso foi de $64 \mu \mathrm{m}$. Vasos $/ \mathrm{mm}^{2}$ - A freqüência média de vasos em Micropholis foi de 25vasos $/ \mathrm{mm}^{2}$. Comprimento médio do elemento de vaso - Devido à ausência de material para preparação de macerado todos os valores foram obtidos na secção tangencial, por isso, não foi possível estabelecer o comprimento de um apêndice ao outro. Desse modo esta característica só poderá ser utilizada para comparação entre os indivíduos analisados unicamente neste trabalho, não sendo parâmetro para discussões com a literatura pesquisada. $A$ média obtida a partir das lâminas analisadas foi de $570 \mu \mathrm{m}$. Tilos e depósitos nos vasos - Foi observada a presença de tilos comuns e esclerificados nos vasos das espécies analisadas. A presença não se aplica a todos os vasos em um mesmo espécime, assim como nem todos os indivíduos apresentaram esta característica (Fig. 51 e 56).

\section{TRAQUEÍDES E FIBRAS}

Traqueídes vasicêntricas e vasculares - A visualização destes elementos em secções longitudinais é muito difícil e a presença de traqueídes não foi diagnosticada. Tipo de pontoação das fibras - As fibras possuem pontoações simples e pontoações com aréola diminuta. Espessamento da parede da fibra - As paredes das fibras são, em geral, espessas. Raramente fibras com paredes muito finas ou muito espessas foram observadas (Fig. 51). 


\section{PARÊNQUIMA AXIAL}

Tipo de Parênquima - As linhas podem variar de uma a duas células de largura (Fig. 50). Célula do parênquima axial: tipo/comprimento da série - Todas as espécies observadas possuem parênquima com oito células por série.

$\underline{\text { RAIOS }}$

Largura do raio - Raios bisseriados predominam no gênero analisado e possuem o corpo composto de duas células de largura e as extremidades unisseriadas. Foi observada a ocorrência de raios com três células de largura em $M$. crassipedicelata, $M$. gardneriana e $M$. porphyrocarpa (Figs. 56-57). Altura - Nenhum raio apresentou altura superior a $1 \mathrm{~mm}$. A média obtida a partir das lâminas analisadas foi de $280 \mu \mathrm{m}$. Composição celular - Esta característica não é facilmente interpretada devido a freqüente ocorrência de raios fusionados. Tanto os raios formados por células procumbentes e mais de quatro células marginais quadradas e/ou eretas quanto os raios formados duas a quatro células marginais ocorreram com a mesma freqüência (Fig. 58). Células perfuradas de raio - Foi observada a presença desse tipo celular esporadicamente em algumas espécies de Micropholis. $O$ fato de células perfuradas não terem sido observadas em todo o gênero não significa que elas não estejam presentes, pois costumam ocorrer em baixa freqüência (IAWA Committee 1989) (Figs. 59-60). Células do parênquima radial com paredes disjuntivas - Foi observada a presença de células disjuntivas em todas as espécies analisadas, notando-se uma diferença na dimensão das projeções, que foram classificadas como longas e curtas (Figs. 61-62). Raios/mm Todas as médias obtidas a partir das espécies analisadas se inseriram na categoria de 4 a 12 raios $/ \mathrm{mm}$ e a média geral do gênero foi de 9 raios $/ \mathrm{mm}$.

\section{INCLUSÕES MINERAIS}

No gênero Micropholis a ocorrência de cristal areniforme foi observada apenas no parênquima axial de M. guianensis subsp. duckeana (Fig. 63). Cristais prismáticos ocorreram no parênquima axial e nos tilos de $M$. egensis (Fig. 64-65) e no parênquima axial e radial de $M$. mensalis. $O$ tipo de inclusão mineral mais visível foram os corpos silicosos, presente nas células do parênquima radial e eventualmente no parênquima axial. No raio, os corpos silicosos foram observados nas células eretas, quadradas e procumbentes de todas as espécies do gênero Micropholis (Figs. 66-67). 


\subsubsection{Gênero Chromolucuma}

As características anatômicas qualitativas e quantitativas da espécie Chromolucuma rubiflora foram condensadas na tabela 5. A lista de características microscópicas da IAWA (IAWA Committee 1989) foi utilizada como parâmetro para as observações. Os resultados foram apresentados de forma descritiva para cada característica analisada. As características que não estão especificadas não se aplicam ou não ocorrem no grupo.

\section{CAMADAS DE CRESCIMENTO}

Não foram observadas camadas de crescimento na espécie analisada (Fig. 68).

\section{$\underline{\text { VASOS }}$}

A porosidade dos vasos é difusa. Arranjo - Na espécie de Chromolucuma avaliada os vasos estão distribuídos de forma difusa (Fig. 68). Agrupamento - Foram observados predominantemente vasos múltiplos de dois e três em Chromolucuma rubiflora (Fig. 68). Placa de perfuração - Em Chromolucuma rubiflora foi observada placa de perfuração simples. Pontoação intervascular - A média para o diâmetro horizontal da câmara da pontoação intervascular foi de $7 \mu \mathrm{m}$, sendo classificada como pequena de acordo com as categorias estabelecidas pela IAWA (IAWA Committee 1989). Pontoação raio-vascular - As pontoações arredondadas com aréolas muito reduzidas a aparentemente simples ocorreram nas células eretas, quadradas e procumbentes e além deste tipo também foram observadas pontoações alongadas horizontalmente à escalariformes nas células eretas, reticuladas nas células quadradas e pontoações semelhantes às intervasculares nas células procumbentes (Fig. 69). Diâmetro tangencial médio do lume do vaso A média para o diâmetro tangencial do lume do vaso em Chromolucuma rubiflora foi de $115 \mu \mathrm{m}$. Vasos $/ \mathrm{mm}^{2}$ - A freqüência média de vasos foi baixa (3 vasos $\left./ \mathrm{mm}^{2}\right)$, ficando estabelecida na categoria de $\leq 5$ vasos $/ \mathrm{mm}^{2}$. Comprimento médio do elemento de vaso - Devido à ausência de material para preparação de macerado todos os valores foram obtidos na secção tangencial, por isso, não foi possível estabelecer o comprimento de um apêndice ao outro. Desse modo esta característica só poderá ser utilizada para comparação entre os indivíduos analisados unicamente neste trabalho, não sendo parâmetro para discussões com a literatura pesquisada. A média obtida para a espécie Chromolucuma rubiflora foi de aproximadamente $650 \mu \mathrm{m}$ se inserindo na categoria de 350 $\mathrm{mm}$ a $800 \mu \mathrm{m}$ estabelecida pela IAWA (IAWA Committee 1989). Tilos e depósitos nos vasos - Não foram observados tilos nos vasos da espécie analisada. 


\section{TRAQUEÍDES E FIBRAS}

Traqueídes vasicêntricas e vasculares - A visualização destes elementos em secções longitudinais é muito difícil entretanto a presença foi diagnosticada esporadicamente. Tipo de pontoação das fibras - Apesar das paredes das fibras serem, em geral, muito espessas, foi possível determinar que as fibras possuem pontoações simples e pontoações com aréola diminuta. Espessamento da parede da fibra - As paredes das fibras são muito espessas (Fig. 68).

\section{PARÊNQUIMA AXIAL}

Tipo de Parênquima - As linhas possuem de uma a duas e eventualmente três células de largura (Fig. 68). Célula do parênquima axial: tipo/comprimento da série - Em Chromolucuma rubiflora predomina o parênquima com oito células por série (Fig. 70).

$\underline{\text { RAIOS }}$

Largura do raio - Os raios são exclusivamente unisseriados (Fig. 71). Altura - A média obtida foi de aproximadamente $450 \mu \mathrm{m}$. Raios de dois tamanhos distintos - Não foi observada a ocorrência de raios de dois tamanhos distintos. Composição celular - Esta característica não é facilmente interpretada devido a freqüente ocorrência de raios fusionados, entretanto em Chromolucuma rubiflora a composição dos raios foi classificada como: células procumbentes, eretas e quadradas misturadas através do raio (Fig. 72). A ocorrência de trabéculas nas células do raio foi observada para esta espécie (Fig. 73). Células perfuradas de raio - Foi observada a presença desse tipo celular em Chromolucuma rubiflora (Fig. 74). Células do parênquima radial com paredes disjuntivas - Foi observada a presença de células disjuntivas com projeções longas (Fig. 75). Raios/mm - As média obtida a partir da espécie analisada foi de 12 raios $/ \mathrm{mm}$.

\section{INCLUSÕES MINERAIS}

Na espécie Chromolucuma rubiflora não foi observado nenhum tipo de cristal tanto nas células do parênquima axial quanto nas do parênquima radial. 0 tipo de inclusão mineral mais visível foram os corpos silicosos, presente nas células do parênquima radial e do parênquima axial. No raio, os corpos silicosos foram observados nas células eretas, quadradas e procumbentes (Fig. 76-77). 


\subsubsection{Gênero Sarcaulus}

As características anatômicas qualitativas e quantitativas das duas espécies de Sarcaulus analisadas foram condensadas na tabela 5. A lista de características microscópicas da IAWA (IAWA Committee 1989) foi utilizada como parâmetro para as observações. Os resultados foram apresentados de forma descritiva para cada característica analisada. As características que não estão especificadas não se aplicam ou não ocorrem no grupo.

\section{CAMADAS DE CRESCIMENTO}

As camadas de crescimento são demarcadas por um achatamento radial das fibras podendo compreender uma linha ou uma faixa com mais de três linhas. Como as fibras não apresentam paredes muito espessas foi observado, além do achatamento, um incremento na espessura destas na região do lenho tardio. Adjacente a estas regiões, ou seja, no limite das camadas de crescimento, também foi observada a ocorrência de parênquima axial achatado radialmente, constituindo o parênquima marginal, assim como a presença de vasos de menor diâmetro (Figs. 78-79).

$\underline{\text { VASOS }}$

Porosidade - Em todos os espécimes analisados, a porosidade é difusa. Arranjo - No gênero Sarcaulus os vasos estão distribuídos de forma radial, predominantemente radial (Fig. 80). Agrupamento - Vasos múltiplos de dois e três são predominantes no gênero Sarcaulus, ocorrendo concomitantemente com vasos solitários (Fig. 81). Placa de perfuração - Em todos os indivíduos do gênero foi observada placa de perfuração simples. Pontoação intervascular - A média para 0 diâmetro horizontal da câmara da pontoação intervascular foi de $5 \mu \mathrm{m}$ no gênero Sarcaulus, sendo classificada como pequena de acordo com as categorias estabelecidas pela IAWA (IAWA Committee 1989). Pontoação raio-vascular - As pontoações arredondadas com aréolas muito reduzidas a aparentemente simples ocorreram nas células eretas, quadradas e procumbentes. Também foram observadas pontoações alongadas horizontalmente à escalariformes nas células eretas, pontoações alongadas horizontalmente a escalariformes, alongadas diagonalmente e reticuladas nas células quadradas e pontoações semelhantes às intervasculares e alongadas horizontalmente nas células procumbentes (Fig. 82). Diâmetro tangencial médio do lume do vaso A média para o diâmetro tangencial do lume do vaso foi de $50 \mu \mathrm{m}$ no gênero Sarcaulus. Vasos $/ \mathrm{mm}^{2}$ - A freqüência de vasos em Sarcaulus assim como em Elaeoluma e Diploon foi uma das mais 
baixas observadas em Sapotaceae, com a ocorrência média de 2vasos $/ \mathrm{mm}^{2}$. Comprimento médio do elemento de vaso - Devido à ausência de material para preparação de macerado todos os valores foram obtidos na secção tangencial, por isso, não foi possível estabelecer o comprimento de um apêndice ao outro. Desse modo esta característica só poderá ser utilizada para comparação entre os indivíduos analisados unicamente neste trabalho, não sendo parâmetro para discussões com a literatura pesquisada. A média obtida a foi de aproximadamente $600 \mu \mathrm{m}$. Tilos e depósitos nos vasos - Foi observada a presença de tilos comuns nos vasos das duas espécies analisadas.

\section{TRAQUEÍDES E FIBRAS}

Traqueídes vasicêntricas e vasculares - A visualização destes elementos em secções longitudinais é muito difícil e não foi observada nesta espécie. Tipo de pontoação das fibras - As fibras possuem pontoações simples e pontoações com aréola diminuta. Espessamento da parede da fibra - As paredes das fibras são, em geral, espessas, tornando-se mais espessas nas regiões do lenho tardio nas camadas de crescimento (Fig. 78).

\section{PARÊNQUIMA AXIAL}

Tipo de Parênquima - As linhas possuem de 1 a 2 células de largura (Figs. 78, 80 e 81). Célula do parênquima axial: tipo/comprimento da série - Em Sarcaulus predomina o parênquima com oito células por série.

$\underline{\text { RAIOS }}$

Largura do raio - Os raios são exclusivamente unisseriados nos cinco espécimes analisados (Fig. 83). Altura - Nenhum raio apresentou altura superior a $1 \mathrm{~mm}$. A média obtida a partir das lâminas analisadas foi de $350 \mu \mathrm{m}$. Composição celular - Esta característica não é facilmente interpretada devido a freqüente ocorrência de raios fusionados. Na maioria das espécies, os raios são formados por células eretas, quadradas e procumbentes misturadas através do raio, entretanto foi observada a ocorrência de raios com mais de quatro células marginais quadradas e/ou eretas e raios formados por duas a quatro células marginais (Fig. 84). Células perfuradas de raio - Não foi observada a presença desse tipo celular nas espécies de Sarcaulus. Células do parênquima radial com paredes disjuntivas - Não foi observada a presença de células disjuntivas em Sarcaulus. Raios $/ \mathrm{mm}$ - A média obtida a partir das duas espécies analisadas foi de 16 raios $/ \mathrm{mm}$. 


\section{INCLUSÕES MINERAIS}

No gênero Sarcaulus não foi observado nenhum tipo de cristal tanto nas células do parênquima axial como nas do parênquima radial. 0 tipo de inclusão mineral mais visível foram os corpos silicosos, presente nas células eretas, quadradas e procumbentes do parênquima radial (Fig. 85-86).

\subsubsection{Gênero Elaeoluma}

As características anatômicas qualitativas e quantitativas das duas espécies de Elaeoluma analisadas foram condensadas na tabela 5. A lista de características microscópicas da IAWA (IAWA Committee 1989) foi utilizada como parâmetro para as observações. Os resultados foram apresentados de forma descritiva para cada característica analisada. As características que não estão especificadas não se aplicam ou não ocorrem no grupo.

\section{CAMADAS DE CRESCIMENTO}

As camadas de crescimento são demarcadas por um achatamento radial das fibras podendo compreender uma faixa com mais de três linhas. Adjacente a estas regiões, ou seja, no limite das camadas de crescimento, também foi observada a presença de vasos de menor diâmetro (Fig. 87).

\section{$\underline{\text { VASOS }}$}

Nos dois espécimes analisados, a porosidade é difusa. Arranjo - No gênero Elaeoluma os vasos estão distribuídos de forma difusa (Fig. 88). Agrupamento - Vasos múltiplos de dois e três são predominantes no gênero Elaeoluma, ocorrendo concomitantemente com vasos solitários (Fig. 89). Placa de perfuração - Em ambos indivíduos da espécie Elaeoluma glabrescens foi observada placa de perfuração simples (Fig. 90). Pontoação intervascular - A média para o diâmetro horizontal da câmara da pontoação intervascular foi de $4 \mu \mathrm{m}$ em Elaeoluma glabrescens, sendo classificada como pequena de acordo com as categorias estabelecidas pela IAWA (IAWA Committee 1989). Pontoação raio-vascular - As pontoações arredondadas com aréolas muito reduzidas a aparentemente simples ocorreram nas células eretas e quadradas. Também foram observadas pontoações alongadas horizontalmente à escalariformes nas células eretas, unilateralmente compostas e escalariformes nas células quadradas e pontoações semelhantes às intervasculares nas células procumbentes (Fig. 91). Diâmetro tangencial médio do lume do vaso - 


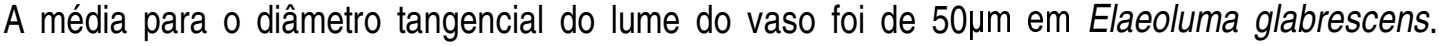
Vasos $/ \mathrm{mm}^{2}$ - A freqüência de vasos em Elaeoluma glabrescens foi uma das mais baixas observadas em Sapotaceae, com a ocorrência de 1 a 2vasos $/ \mathrm{mm}^{2}$ (Fig. 92). Comprimento médio do elemento de vaso - Devido à ausência de material para preparação de macerado todos os valores foram obtidos na secção tangencial, por isso, não foi possível estabelecer o comprimento de um apêndice ao outro. Desse modo esta característica só poderá ser utilizada para comparação entre os indivíduos analisados unicamente neste trabalho, não sendo parâmetro para discussões com a literatura pesquisada. A média obtida a partir dos dois espécimes de Elaeoluma glabrescens analisados foi de aproximadamente $600 \mu \mathrm{m}$ se inserindo na categoria de $350 \mu \mathrm{m}$ a $800 \mu \mathrm{m}$ estabelecida pela IAWA (IAWA Committee 1989). Tilos e depósitos nos vasos - Foi observada a presença de tilos comuns apenas no espécime Aw27492.

\section{TRAQUEÍDES E FIBRAS}

Traqueídes vasicêntricas e vasculares - A visualização destes elementos em secções longitudinais é muito difícil e não foi observada nesta espécie. Tipo de pontoação das fibras - As fibras possuem pontoações simples e pontoações com aréola diminuta. Espessamento da parede da fibra - As paredes das fibras foram consideradas muito finas (Fig. 87).

\section{PARÊNQUIMA AXIAL}

Tipo de Parênquima - Em Elaeoluma glabrescens o parênquima foi classificado como difuso em agregados, ou seja, tendendo a formar linhas (Figs. 87-89). Célula do parênquima axial: tipo/comprimento da série - Em Elaeoluma glabrescens predomina o parênquima com oito células por série.

\section{$\underline{\text { RAIOS }}$}

Largura do raio - Os raios apresentaram de uma a três células de largura (Fig. 93). Altura Nenhum raio apresentou altura superior a $1 \mathrm{~mm}$ e a média foi estabelecida em torno de $350 \mu \mathrm{m}$. Composição celular - Foram observados raios constituídos por um corpo central de células procumbentes e células marginais quadradas e/ou eretas compondo a margem, com duas a quatro camadas ou com mais de quatro camadas (Fig. 94). Células perfuradas de raio - Não foi observada a presença desse tipo celular em Elaeoluma glabrescens. Células do parênquima radial com paredes disjuntivas - Foi observada a presença de células disjuntivas com projeções longas (Fig. 95). Raios/mm - A média obtida a partir dos dois espécimes analisados foi de $11 \mathrm{raios} / \mathrm{mm}$. 


\section{INCLUSÕES MINERAIS}

No gênero Elaeoluma não foi observado nenhum tipo de cristal ou de corpos silicosos nas células do parênquima axial e radial.

\subsubsection{Gênero Ecclinusa}

As características anatômicas qualitativas e quantitativas das espécies de Ecclinusa avaliadas foram condensadas na tabela 6. A lista de características microscópicas da IAWA (IAWA Committee 1989) foi utilizada como parâmetro para as observações. Os resultados foram apresentados de forma descritiva para cada característica analisada. As características que não estão especificadas não se aplicam ou não ocorrem no grupo.

\section{CAMADAS DE CRESCIMENTO}

As camadas de crescimento estão presentes e são demarcadas por um achatamento radial das fibras podendo compreender uma linha ou uma faixa com mais de três linhas. Nas espécies em que as fibras apresentam paredes pouco espessas foi observado, além do achatamento, um incremento na espessura das paredes na região do lenho tardio. Adjacente a estas regiões, ou seja, no limite das camadas de crescimento, também foi observada a ocorrência de vasos de menor diâmetro (Fig. 96).

\section{$\underline{\text { VASOS }}$}

Porosidade - Em todos os espécimes analisados, a porosidade é difusa. Arranjo - No gênero Ecclinusa os vasos estão distribuídos de forma radial e/ou diagonal (Fig. 97). Agrupamento - Vasos múltiplos de dois e três são predominantes no gênero Ecclinusa, ocorrendo concomitantemente com vasos solitários e múltiplos de quatro ou mais (Fig. 98). Placa de perfuração - Em todos os indivíduos do gênero foi observada placa de perfuração simples, entretanto resíduos de placas de perfuração escalariforme foram obervados (Figs. 99-101). Pontoação intervascular - A média para o diâmetro horizontal da câmara da pontoação intervascular foi de $5 \mu \mathrm{m}$ no gênero Ecclinusa, sendo classificada como pequena de acordo com as categorias estabelecidas pela IAWA (IAWA Committee 1989). Pontoação raio-vascular - As pontoações arredondadas com aréolas muito reduzidas a aparentemente simples ocorreram nas células eretas, quadradas e procumbentes e além deste tipo também foram observadas pontoações 
alongadas horizontalmente à escalariformes nas células eretas; reticuladas e alongadas horizontalmente à escalariformes nas células quadradas; e pontoações semelhantes às intervasculares nas células procumbentes (Figs. 102-103). Diâmetro tangencial médio do lume do vaso - A média para o diâmetro tangencial do lume do vaso foi de $50 \mu \mathrm{m}$. Vasos $/ \mathrm{mm}^{2}$ - A freqüência de vasos em Ecclinusa assim como em Diploon foi uma das mais baixas observadas em Sapotaceae, com a ocorrência média de 3vasos $/ \mathrm{mm}^{2}$. Comprimento médio do elemento de vaso A média obtida a foi de aproximadamente $300 \mu \mathrm{m}$. Tilos e depósitos nos vasos - Foi observada a presença de tilos comuns nos vasos das duas espécies analisadas (Figs. 98 e 104). A presença não se aplica a todos os vasos em um mesmo espécime, assim como nem todos os indivíduos apresentaram esta característica.

\section{TRAQUEÍDES E FIBRAS}

Traqueídes vasicêntricas e vasculares - A visualização destes elementos em secções longitudinais é muito difícil entretanto a presença foi diagnosticada em alguns espécimes. Tipo de pontoação das fibras - As fibras possuem pontoações simples e pontoações com aréola diminuta. Espessamento da parede da fibra - As paredes das fibras são, finas a espessas (Figs. 96 e 98).

\section{PARÊNQUIMA AXIAL}

Tipo de Parênquima - As linhas podem variar de uma a duas células de largura (Figs. 9698).

Célula do parênquima axial: tipo/comprimento da série - Em Ecclinusa predomina o parênquima com oito células por série.

\section{$\underline{\text { RAIOS }}$}

Largura do raio - Em E. lanceolata os raios são exclusivamente unisseriados e em $E$. guianensis predominam os raios bisseriados (Figs. 105-106). Altura - A média da altura do raio foi de $300 \mu \mathrm{m}$. Composição celular - Esta característica não é facilmente interpretada devido a freqüente ocorrência de raios fusionados. Na maioria das espécies, os raios são formados por células procumbentes e de duas a quatro células marginais quadradas e/ou eretas (Figs. 107-108). Células perfuradas de raio - Foi observada a presença desse tipo celular nas duas espécies analisadas (Fig. 109). Células do parênquima radial com paredes disjuntivas - Foi observada a presença de células disjuntivas com projeções longas e curtas (Fig. 110-112). Raios/mm - A freqüência de raios foi de 13 raios $/ \mathrm{mm}$. 


\section{INCLUSÕES MINERAIS}

No gênero Ecclinusa não foi observado nenhum tipo de cristal tanto nas células do parênquima axial quanto nas do parênquima radial. 0 tipo de inclusão mineral mais visível foram os corpos silicosos, presente nas células do parênquima radial (Fig. 113).

\subsubsection{Gênero Pradosia}

As características anatômicas qualitativas e quantitativas de espécies de Pradosia observadas foram condensadas na tabela 6. A lista de características microscópicas da IAWA (IAWA Committee 1989) foi utilizada como parâmetro para as observações. Os resultados foram apresentados de forma descritiva para cada característica analisada. As características que não estão especificadas não se aplicam ou não ocorrem no grupo.

\section{CAMADAS DE CRESCIMENTO}

As camadas de crescimento são demarcadas por um achatamento radial das fibras podendo compreender uma linha ou uma faixa com mais de três linhas, assim como a presença de vasos de menor diâmetro. Adjacente a estas regiões, ou seja, no limite das camadas de crescimento em $P$. colombiana, $P$. atroviolacea e $P$. cochelaria subsp. praealta também foi observada a ocorrência de uma ou mais linhas de parênquima axial achatadas radialmente, constituindo o parênquima marginal (Figs. 114-116 e 125).

\section{VASOS}

Porosidade - Em todos os espécimes analisados, a porosidade é difusa. Arranjo - No gênero Pradosia os vasos estão distribuídos de forma difusa (Figs. 114-116). Agrupamento Vasos múltiplos de dois e três são predominantes no gênero Pradosia, ocorrendo concomitantemente com vasos solitários e eventualmente múltiplos de quatro ou mais (Figs. 114116). Placa de perfuração - Em Pradosia foi observada a ocorrencia de duas placas simples muito proximas uma da outra sem que pudesse ser notado o limite entre a presenca de duas placas e a presenca de uma placa multipla com uma barra (Figs. 117-122). Pontoação intervascular - A média para o diâmetro horizontal da câmara da pontoação intervascular foi de aproximadamente $5 \mu \mathrm{m}$ no gênero Pradosia, sendo classificada como pequena de acordo com as categorias estabelecidas pela IAWA (IAWA Committee 1989). Pontoação raio-vascular - Houve uma ampla variação no tipo e 
localização das pontoações raio-vasculares no gênero Pradosia. Com exceção das pontoações semelhantes às intervasculares, as demais apresentaram aréolas muito reduzidas a aparentemente simples. Nas células eretas do raio prevaleceram as pontoações alongadas horizontalmente à escalariformes. Nas células quadradas, houve uma distribuição mais uniforme entre os seguintes tipos de pontoação: arredondadas com aréolas muito reduzidas a aparentemente simples; alongadas diagonalmente com aréolas muito reduzidas a aparentemente simples; e alongadas horizontalmente; reticuladas e pontoações de dois tipos na mesma célula. Nas células procumbentes, as pontoações semelhantes às intervasculares foram predominantes (Figs. 123124). Diâmetro tangencial médio do lume do vaso - A média para o diâmetro tangencial do lume do vaso foi de aproximadamente $60 \mu \mathrm{m}$. Apenas $P$. montana apresentou diâmetro menor, $36 \mu \mathrm{m}$. Vasos $/ \mathrm{mm}^{2}$ - A freqüência média de vasos em Pradosia foi de 6vasos $/ \mathrm{mm}^{2}$. Comprimento médio do elemento de vaso - Devido à ausência de material para preparação de macerado todos os valores foram obtidos na secção tangencial, por isso, não foi possível estabelecer o comprimento de um apêndice ao outro. Desse modo esta característica só poderá ser utilizada para comparação entre os indivíduos analisados unicamente neste trabalho, não sendo parâmetro para discussões com a literatura pesquisada. A média obtida a foi de aproximadamente $600 \mu \mathrm{m}$.

Tilos e depósitos nos vasos - Foi observada a presença de tilos comuns nos vasos das espécies analisadas. A presença não se aplica a todos os vasos em um mesmo espécime, assim como nem todos os indivíduos apresentaram esta característica (Fig. 125).

\section{TRAQUEÍDES E FIBRAS}

Traqueídes vasicêntricas e vasculares - A visualização destes elementos em secções longitudinais é muito difícil e não foi possível determinar a presença de tais tipos celulares no material analisado. Tipo de pontoação das fibras - Apesar das paredes das fibras serem, em geral, muito espessas, foi possível determinar que as fibras possuem pontoações simples e pontoações com aréola diminuta. Espessamento da parede da fibra - As paredes das fibras são muito espessas (Fig. 125).

\section{PARÊNQUIMA AXIAL}

Tipo de Parênquima - Na maioria das espécies o parênquima é composto de três células de largura, entretanto em $P$. schomburgkiana subsp. schomburgkiana e $P$. cuatrecasii as linhas apresentam duas células de largura (Figs. 114-116). Célula do parênquima axial: tipo/comprimento 
da série - Em Pradosia predomina o parênquima com oito células por série, entretanto foi observada a ocorrência de séries compostas por mais de oito células em $P$. cuatrecasii.

$\underline{\text { RAIOS }}$

Largura do raio - Raios bisseriados predominam em Pradosia e raios com até três células de largura ocorrem em P. atroviolacea, P. cochelaria subsp. praealta e P. montana (Fig. 126). Altura - Nenhum raio apresentou altura superior a $1 \mathrm{~mm}$ e a média foi estabelecida em torno de $350 \mu \mathrm{m}$. Composição celular - Foram observados raios constituídos por um corpo central de células procumbentes e normalmente mais de quatro camadas de células marginais quadradas e/ou eretas. Esporadicamente alguns raios com duas a quatro células marginais foram observados (Fig. 127). Células perfuradas de raio - Foi observada a presença desse tipo celular apenas em um espécime de P. schomburgkiana subsp. schomburgkiana (SJRw 32640) (Fig. 128). Células do parênquima radial com paredes disjuntivas - Foi observada a presença de células disjuntivas com projeções curtas em todas as espécies analisadas (Figs. 129-130). Raios/mm - As média obtida para 0 gênero foi de 12 raios $/ \mathrm{mm}$.

\section{INCLUSÕES MINERAIS}

Foi observada a presença de cristais areniformes no parênquima axial de todas as espécies estudadas e esporadicamente estes tipos de cristais ocorreram nas células do raio. Corpos silicosos foram diagnosticados nas células do parênquima radial e eventualmente no parênquima axial. No raio, os corpos silicosos foram observados nas células eretas, quadradas e procumbentes (Fig. 131).

\subsubsection{Gênero Pouteria}

As características anatômicas qualitativas e quantitativas das espécies de Pouteria avaliadas, que ocorrem no continente americano, incluídas em oito das nove seções propostas por Pennington (1990, 1991), foram condensadas na tabela 7. A lista de características microscópicas da IAWA (IAWA Committee 1989) foi utilizada como parâmetro para as observações. Os resultados foram apresentados de forma descritiva para cada característica analisada. As características que não estão especificadas não se aplicam ou não ocorrem no grupo. 


\section{CAMADAS DE CRESCIMENTO}

As camadas de crescimento podem estar presentes ou ausentes. Quando presentes são demarcadas por um achatamento radial das fibras podendo compreender uma linha ou uma faixa com mais de três linhas. Nas espécies em que as fibras apresentam paredes pouco espessas foi observado, além do achatamento, um incremento na espessura das paredes na região do lenho tardio. Adjacente a estas regiões, ou seja, no limite das camadas de crescimento, também foi observada a ocorrência de uma ou mais linhas de parênquima axial achatadas radialmente, constituindo o parênquima marginal, assim como a presença de vasos de menor diâmetro. A ocorrência de zonas fibrosas foi observada esporadicamente no gênero Pouteria, predominando na Seção Aneulucuma. Esta característica pode ou não estar associada com os marcadores descritos anteriormente e foi definida como uma região na qual ocorre a diminuição de linhas do parênquima axial na direção do lenho tardio, resultando em áreas onde predominam fibras e poucos vasos, denominadas zonas fibrosas. (Figs. 132-140).

\section{$\underline{\text { VASOS }}$}

Em todos os espécimes analisados, a porosidade é difusa. Arranjo - No gênero Pouteria os vasos estão distribuídos de forma difusa, principalmente nas espécies da seção Pouteria, Oligotheca, Rivicoa, Antholucuma e Aneulucuma. Na seção Franchetella foi observada uma predominância na distribuição radial e/ou diagonal sobre a distribuição difusa e em Oxythece e Gayella foram observados, unicamente, os arranjos radial e/ou diagonal (Figs. 141-144). Agrupamento - Vasos múltiplos de dois e três são predominantes no gênero Pouteria, ocorrendo concomitantemente com vasos solitários e múltiplos de quatro ou mais. Estes ocorreram, pontualmente, como maioria, em alguns espécimes das seções Franchetella ( $P$. trilocularis MADw 19022 e P. trilocularis MADw 18 697), Oxythece (P. elegans SJRw 54 203; P. cuspidata Aw 27369 e P. cuspidata Aw 27405), Rivicoa (P. campechiana) e Antholucuma (P. trigonosperma) (Figs. 141144). Placa de perfuração - Em todos os indivíduos do gênero foi observada placa de perfuração simples (Figs. 145-146). Pontoação intervascular - A média para o diâmetro horizontal da câmara da pontoação intervascular foi de $5 \mu \mathrm{m}$ no gênero Pouteria, sendo classificada como pequena de acordo com as categorias estabelecidas pela IAWA (IAWA Committee 1989). Entretanto a variação

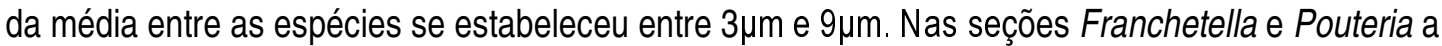
variação foi semelhante à observada para o gênero e somente nestas seções pontoações muito pequenas e médias foram observadas. Nas demais seções, Oxythece, Oligotheca, Rivicoa, Antholucuma, Aneulucuma e Gayella, todas as médias foram estabelecidas na classe de 4-7 $\mu \mathrm{m}$, ou 
seja, pontoações intervasculares pequenas. Pontoação guarnecida - Não foi observada a ocorrência deste tipo de pontoação no gênero Pouteria. Pontoação raio-vascular - Houve uma ampla variação no tipo e localização das pontoações raio-vasculares no gênero Pouteria. Com exceção das pontoações semelhantes às intervasculares, as demais apresentaram aréolas muito reduzidas a aparentemente simples. A variação entre as pontoações horizontais (escalariformes) a verticais (paliçada) também foi considerada, de acordo com os critérios definidos em Material e Métodos. Nas células eretas do raio prevaleceram as pontoações alongadas horizontalmente à escalariformes. Nas células quadradas, houve uma distribuição mais uniforme entre os seguintes tipos de pontoação: arredondadas com aréolas muito reduzidas a aparentemente simples; reticuladas; alongadas diagonalmente com aréolas muito reduzidas a aparentemente simples; e alongadas horizontalmente à escalariformes. Nas células procumbentes, as pontoações semelhantes às intervasculares foram predominantes. Também foram observadas, em menor freqüência, pontoações alongadas verticalmente à paliçada, pontoações unilateralmente compostas e pontoações de dois tipos na mesma célula. Com exceção das seções Oxythece, Rivicoa e Antholucuma a distribuição dos tipos de pontoações nas células do raio foi semelhante à distribuição no gênero. Nas seções Oxythece e Rivicoa o tipo pontoação arredondada com aréola muito reduzida a aparentemente simples ocorreu com a mesma freqüência do tipo pontoação semelhante à intervascular nas células procumbentes. Já na seção Antholucuma, o tipo pontoação unilateralmente composta ocorreu com a mesma freqüência do tipo semelhante à intervascular nas células quadradas e procumbentes (Figs. 147-149). Espessamento espiralado - Não foram observados. Diâmetro tangencial médio do lume do vaso - A média para o diâmetro tangencial do lume do vaso foi de $78 \mu m$ no gênero Pouteria. A variação do valor médio entre as espécies se

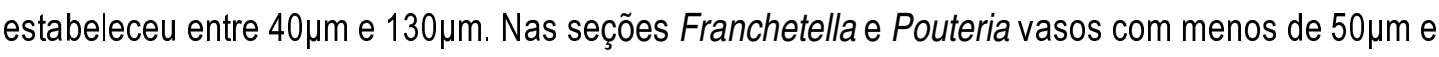
vasos com mais de $100 \mu m$ de diâmetro foram notados. Nas demais seções a variação das médias

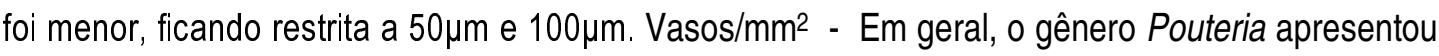
freqüências nos limites da categoria de 5 a 20 vasos $/ \mathrm{mm}^{2}$, conforme o padrão da IAWA (IAWA Committee 1989). A seção Franchetella foi a única em que a média se estabeleceu na categoria de 20 a 40 vasos $/ \mathrm{mm}^{2}$, embora freqüências inferiores a 20 vasos $/ \mathrm{mm}^{2}$ tenham sido obtidas para seis espécies. Comprimento médio do elemento de vaso - Devido à ausência de material para preparação de macerado todos os valores foram obtidos na secção tangencial, por isso, não foi possível estabelecer o comprimento de um apêndice ao outro. Desse modo esta característica só poderá ser utilizada para comparação entre os indivíduos analisados unicamente neste trabalho, não sendo parâmetro para discussões com a literatura pesquisada. Todas as médias obtidas a partir 
das lâminas analisadas variaram de aproximadamente $500 \mu \mathrm{m}$ a $750 \mu \mathrm{m}$ se inserindo na categoria de $350 \mu \mathrm{m}$ a $800 \mu \mathrm{m}$ estabelecida pela IAWA (IAWA Committee 1989). Tilos e depósitos nos vasos - Foi observada a presença de tilos comuns e esclerificados nos vasos das espécies analisadas. A presença não se aplica a todos os vasos em um mesmo espécime, assim como nem todos os indivíduos apresentaram esta característica (Figs. 150-152).

\section{TRAQUEÍDES E FIBRAS}

Traqueídes vasicêntricas e vasculares - A visualização destes elementos em secções longitudinais é muito difícil entretanto a presença foi diagnosticada em algumas espécies em que foi possível a preparação do macerado (Fig. 153). Tipo de pontoação das fibras - Apesar das paredes das fibras serem, em geral, muito espessas, foi possível determinar que as fibras possuem pontoações simples e pontoações com aréola diminuta. Espessamento da parede da fibra - As paredes das fibras são, em geral, muito espessas. Raramente fibras com paredes muito finas ocorrem em Pouteria, exceto em P. laevigata (Seção Oligotheca), P. franciscana e P. gomphiifolia (Seção Pouteria). Foi observada, esporadicamente, em alguns espécimes, a presença de fibras gelatinosas (Figs. 153-155).

\section{PARÊNQUIMA AXIAL}

Tipo de Parênquima - As linhas podem variar de apenas uma célula de largura ( $P$. guianensis - Fróes 407); ou linhas com duas a três células de largura (maioria), até linhas com mais de quatro células de largura ( $P$. glomerata subsp. glomerata e P. plicata) (Figs. 156-158). Célula do parênquima axial: tipo/comprimento da série - Em Pouteria predomina o parênquima com oito células por série, entretanto foi observada a ocorrência de séries compostas por quatro células na seção Oligotheca, assim como séries com mais de oito células na Seção Oxythece. Em P. cuspidata subsp. robusta foi diagnosticada a presença de parênquima gelatinoso (Figs. 159-161).

$\underline{\text { RAIOS }}$

Largura do raio - Na maioria das vezes os raios são unisseriados e bisseriados, porém raios bisseriados predominam em todas os espécimes analisados e possuem o corpo composto de duas células de largura $e$ as extremidades unisseriadas. Ocasionalmente os raios são exclusivamente unisseriados, incluídos nesta categoria estão Pouteria lucumifolia, $P$. gongrijpii, $P$. sagotiana, $P$. williamii e P. trilocularis (Seção Franchetella); $P$. cuspidata subsp. cuspidata, $P$. cuspidata subsp. dura (Seção Oxythece); P. rodriguesiana (Seção Rivicoa); P. venosa subsp. amazonica e $P$. trigonosperma (Seção Antholucuma) e $P$. caimito, $P$. torta subsp. tuberculata, $P$. 
torta subsp. glabra e $P$. hispida (Seção Pouteria). Raramente os raios possuem mais de duas células de largura e raios com três a cinco células foram observados em alguns espécimes da seção Pouteria (Figs. 162-163). Altura - Nenhum raio apresentou altura superior a $1 \mathrm{~mm}$. Todas as médias obtidas a partir das lâminas analisadas variaram de aproximadamente $300 \mu \mathrm{m}$ a $500 \mu \mathrm{m}$. Composição celular - Esta característica não é facilmente interpretada devido a freqüente ocorrência de raios fusionados. Na maioria das espécies, os raios são formados por células procumbentes e mais de quatro células marginais quadradas e/ou eretas nas extremidades. Raios formados por uma célula marginal e raios formados duas a quatro células marginais ocorreram com a mesma freqüência. Raios com células procumbentes, eretas e quadradas misturadas foram observados em poucos espécimes. Nas seções Franchetella, Rivicoa e Gayella houve predominância de raios com apenas uma camada de células marginais quadradas e/ou eretas e em Oxythece raios com duas a quatro células marginais ocorreram em maioria. Nas seções Oligotheca, Pouteria e Aneulucuma foi observado um maior número de raios formados por células procumbentes (corpo) e mais de quatro células marginais quadradas e/ou eretas marginais (Figs.164-165). Em P. gabrielensis foi observada a ocorrência de trabéculas nas células do raio. Esta característica também foi observada em espécies de outros gêneros de Sapotaceae. Células perfuradas de raio - Foi observada a presença desse tipo celular em espécies das seções Franchetella, Oxythece, Oligotheca e Pouteria. O fato de células perfuradas não terem sido observadas em todo o gênero não significa que elas não estejam presentes, pois costumam ocorrer em baixa freqüência (IAWA Committee 1989) (Fig. 166). Células do parênquima radial com paredes disjuntivas - Foi observada a presença de células disjuntivas em praticamente todas as espécies analisadas com ressalva para as representadas na seção Rivicoa. Nas demais, notou-se uma diferença na dimensão das projeções, que foram classificadas como longas e curtas. Raios/mm Todas as médias obtidas a partir das espécies analisadas se inseriram na categoria $\geq 12$ raios $/ \mathrm{mm}$. Dessas destaca-se a seção Franchetella, cuja média foi de 20 raios $/ \mathrm{mm}$.

\section{INCLUSÕES MINERAIS}

No gênero Pouteria não foi observado nenhum tipo de cristal tanto nas células do parênquima axial quanto nas do parênquima radial. O tipo de inclusão mineral mais visível foram os corpos silicosos, presente nas células do parênquima radial e eventualmente no parênquima axial. No raio, os corpos silicosos foram observados nas células eretas, quadradas e procumbentes e todos os espécimes do gênero Pouteria analisados apresentaram esta característica (Fig. 167). 


\subsubsection{Gênero Chrysophyllum}

As características anatômicas qualitativas e quantitativas das espécies de Chrysophyllum analisadas, que ocorrem no continente americano, incluídas nas cinco seções propostas por Pennington $(1990,1991)$, foram condensadas na tabela 8.

\section{CAMADAS DE CRESCIMENTO}

As camadas de crescimento podem estar presentes ou ausentes. Quando presentes são demarcadas por um achatamento radial das fibras. Adjacente a estas regiões, ou seja, no limite das camadas de crescimento, também foi observada a ocorrência de parênquima axial achatado radialmente, constituindo o parênquima marginal, assim como a presença de vasos de menor diâmetro (Figs. 168-171).

\section{VASOS}

Porosidade - Em todos os espécimes analisados, a porosidade é difusa. Arranjo - $\mathrm{Na}$ seção Chrysophyllum e Villocuspis os vasos estão distribuídos de forma difusa (Fig.168). Nas seções Ragala e Prieurella predomina a distribuição radial e/ou diagonal. $\mathrm{Na}$ seção Aneuchrysophyllum os vasos podem estar dispostos de forma difusa, radial e/ou diagonal ou ainda dendrítica (Fig. 172). Agrupamento - Vasos múltiplos de dois e três são predominantes no gênero Chrysophyllum (Figs.168 e 170), ocorrendo concomitantemente com vasos solitários e múltiplos de quatro ou mais. Estes ocorreram, predominantemente, na seção Aneuchrysophyllum (Fig. 172). Placa de perfuração - Em todos os indivíduos do gênero foi observada placa de perfuração simples e em C. cuneifolium, além de placa simples foi observada a ocorrência esporádica de placa de perfuração escalariforme com até 3 barras (Fig. 173). Pontoação intervascular - A média para 0 diâmetro horizontal da câmara da pontoação intervascular foi de $5 \mu$ m. Pontoação raio-vascular As pontoações arredondadas com aréolas muito reduzidas a aparentemente simples ocorreram nas células eretas, quadradas e procumbentes e além deste tipo também foram observadas pontoações alongadas horizontalmente à escalariformes nas células eretas; reticuladas, alongadas horizontalmente à escalariformes e alongadas diagonalmente nas células quadradas; e pontoações semelhantes às intervasculares e alongadas verticalmente nas células procumbentes (Figs. 174176). Diâmetro tangencial médio do lume do vaso - A média para o diâmetro tangencial do lume do vaso foi de $80 \mu \mathrm{m}$. Vasos $/ \mathrm{mm}^{2}$ - A média foi de 20 vasos $/ \mathrm{mm}^{2}$. Na seção Ragalla a média foi a menor, com apenas 7 vasos $/ \mathrm{mm}^{2}$. Comprimento médio do elemento de vaso - 0 comprimento 
médio do elemento de vaso foi de 650 $\mu \mathrm{m}$. Tilos e depósitos nos vasos - Foi observada a presença de tilos comuns e esclerificados nos vasos das espécies analisadas. A presença não se aplica a todos os vasos em um mesmo espécime, assim como nem todos os indivíduos apresentaram esta característica (Figs. 168-169 e 178).

\section{TRAQUEÍDES E FIBRAS}

Traqueídes vasicêntricas e vasculares - A visualização destes elementos em secções longitudinais é muito difícil e não pode ser diagnosticada nas espécies analisadas. Tipo de pontoação das fibras - Apesar das paredes das fibras serem, em geral, muito espessas, foi possível determinar que as fibras possuem pontoações simples e pontoações com aréola diminuta. Espessamento da parede da fibra - As paredes das fibras são, em geral, muito espessas e raramente fibras com paredes muito finas ocorrem em Chrysophyllum, exceto em $C$. venezuelanense (Seção Aneuchrysophyllum) (Figs. 169 e 177).

\section{PARÊNQUIMA AXIAL}

Tipo de Parênquima - As linhas podem variar de uma a duas células de largura e em $C$. lucentifolium subsp. pachycarpum o parênquima possui três células de largura (Figs. 168-172). Célula do parênquima axial: tipo/comprimento da série - Em Chrysophyllum predomina 0 parênquima com 8 células por série, entretanto foi observada a ocorrência de séries compostas por mais de oito células em $C$. ferrugineum,. $C$. cainito e $C$. sparsiflorum.

$\underline{\text { RAIOS }}$

Largura do raio - Raios bisseriados predominam, podendo ocorrer concomitantemente com raios unisseriados. Raios exclusivamente unisseriados estão presentes em C. cainito, C. acreanum e C. cuneifolium (Fig. 178). Raios com três e quatro células de largura também foram observados em alguns espécimes e predominam na seção Aneuchrysophyllum (Fig. 179). Altura - A altura

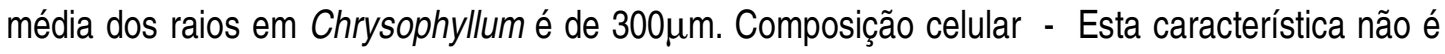
facilmente interpretada devido a freqüente ocorrência de raios fusionados. Na maioria das espécies, os raios são formados por células procumbentes e de duas a quatro células marginais quadradas e/ou eretas. Raios formados por mais de quatro células marginais e raios com células procumbentes, eretas e quadradas misturadas foram observados em poucos espécimes (Figs. 180181). Foi notada a ocorrência de trabéculas nas células do raio em alguns espécimes observados (Figs. 182-183). Células perfuradas de raio - Foi observada a presença desse tipo celular em cinco 
espécies da seção Chrysophyllum. O fato de células perfuradas não terem sido observadas em todo o gênero não significa que elas não estejam presentes, pois costumam ocorrer em baixa freqüência (IAWA Committee 1989). Células do parênquima radial com paredes disjuntivas - Foi observada a presença de células disjuntivas com projeções longas e curtas em praticamente todas as espécies analisadas (Fig. 184). Raios/mm - A freqüência média de raios foi de 12 raios $/ \mathrm{mm}$.

\section{INCLUSÕES MINERAIS}

Cristais areniformes foram observados no parênquima axial das espécies da seção Aneuchrysophyllum e nas células do raio de $C$. venezuelanense pertencente à mesma seção (Figs. 186-189). Cristais prismáticos foram obervados esporadicamente no raio e no parênquima axial. Em C. argenteum subsp. auratum e $C$. oliviforme subsp. oliviforme foi verificada a ocorrencia de cristais prismáticos nos tilos (Figs. 190-191). Corpos silicosos, estão presentes nas células do parênquima radial, mas não são comuns na seção Aneuchrysophyllum. No raio, os corpos silicosos foram observados nas células eretas, quadradas e procumbentes (Figs. 182-183).

\section{Discussão}

As características anatômicas do lenho de Pouteria (sensu Pennington, 1990) são muito semelhantes às relatadas por Kukachka (1982d), assim como as espécies, em geral, são muito semelhantes entre si, fato que reforça a estreita relação entre os componentes de Pouteria. Não foram observadas características que representam sinapomorfias nas tribos propostas por Pennington (1990), ou seja, em algumas tribos há predominância de determinada característica, entretanto a mesma situação pode ser observada em outros grupos esporadicamente.

Algumas características não variam entre os indivíduos analisados, por isso não possuem valor diagnóstico para separar as espécies. Dentre estas características pode-se citar a porosidade difusa dos vasos e a placa de perfuração simples.

O arranjo dos vasos deverá ser explorado de maneira mais precisa em uma próxima análise pois a ocorrência de vasos com arranjo radial e/ou diagonal é típica dos indivíduos dessa família, entretanto uma possível predominância de um tipo ou outro não foi determinada. A pontoação radiovascular típica de Sapotaceae que ocorre em Pouteria possui aréolas muito reduzidas a aparentemente simples: horizontais (escalariformes) a verticais (paliçada), entretanto a localização deste tipo de pontoação nas células do raio não foi observada, sendo alvo de futura análise. A 
presença de sílica nos raios é uma característica observada em todos os espécimes, entretanto a localização e o tamanho dos grãos deverão ser analisados.

As diferenças interespecíficas observadas e que serão avaliadas quanto à possível utilização como caráter taxonômico, são as seguintes: camadas de crescimento, agrupamento dos vasos, tamanho da pontoação intervascular, presença de espessamento espiralado nos elementos de vaso, diâmetro dos vasos, presença de traqueídes, largura dos raios e composição celular dos raios, dentre outras características quantitativas que serão obtidas com a análise de material de macerado.

Assim sendo, espera-se que as diferenças anatômicas em conjunto com as informações morfológicas, químicas e de pólen, que serão alvo do próximo estudo, sejam suficientes para permitir inferências acerca da posição destes taxa dentro das seções.

\section{Referências bibliográficas}

Anderberg, A. A., C. Rydin, et al. (2002). "Phylogenetic relationships in the order Ericales s.l.: analyses of molecular data from five genes from the plastid and mitochondrial genomes." American Journal of Botany 89(4): 677-687.

Aubréville, A. 1964. Les Sapotacées taxonomie et phytogeographie. Adansonia, Mé. 1: 1-157.

Baehni, C. 1938. Mémoires sur les sapotacées. 1. Systeme de classification. Candollea 7: 394508.

Baehni, C. 1965. Mémoires sur les sapotacées. 3. Inventaire de genres. Boissiera 11: 1-262.

Baker, R. T. 1919. The hardwoods of Australia and their economics. 522p.

Barajas Morales, J.; Rebollar Domínguez, S.; Echenique-Manrique, R. 1979. Anatomía de maderas de México. oㅡ 2. Veinte especies de la Selva Lacandona. Biotica, Méx. 4:163-193.

BREMER, K. 1988. The limits of amino acid sequence data in angiosperm phylogenetic reconstruction. Evolution 42: 795-803.

Council for Scientific and Industrial Research. Division of forest Products. 1933. The Growth and Structure of Wood. H. J. Green, Government Printer, Melbourne. p 65-67. 
Cozzo, D. 1951. Investigaciones anatómicas en maderas de Sapotáceas argentinas. Ver. Mus. Argent. Ci. Nat. "Bernardino Rivadavia", Ci. Bot. 2:263-290.

Dadswell, H. E. \& Eckersley, A. M. 1935. The identification of the principal commercial Australian timbers other than eucalypts. C.S.I.R. Bulletin no 90; Division of Forest Products, Melbourne, Tech. Paper no 16. 103pp.

Détienne, P. \& Jacquet, P. 1983. Atlas d'identification des bois de l'Amazonie et des régions voisines. Centre Tech. for. Trop.: Nogent-sur-Marne. 640pp.

FelsensteIn, J. 1985. Confidence-limits on phylogenies - an approach using the bootstrap. Evolution 39: 783-791.

Gasson, P. (1996). "Wood anatomy of the tribe swartzieae with comments on related papilionoid and caesalpinioid leguminosae." IAWA Journal 17(1): 45-75.

Gilly, C. L. 1943. Studies in Sapotaceae, II. The sapodilla-níspero complex. Trop. Woods. 73:1-22.

Graham, S. A., J. V. Crisci, et al. (1993). "Cladistic analysis of the Lytraceae sensu lato based on morphological characters." Botanical Journal of the Linnean Society 113: 1-33.

Honda, M. 1971. Contribuição ao estudo anatômico do lenho de cinco Sapotaceae da Amazônia. Acta Amazonica 1(3):71-83.

Hufford, L. (1992). "Rosidae and their relationships to other nonmagnoliid dicotyledons: a phylogenetic analysis using morphological and chemical data." Annals of the Missouri Botanical Garden 79: 218-248.

IAWA Committee 1989. IAWA List of Microscopic Features for Hardwood Identification.E. A. Wheeler, P. Baas \& P. Gasson (eds.). IAWA Bulletin n.s. 10(3): 219-332.

Kanehira, R. 1921. Anatomical characters and identification of Formosan woods. Government of Formosa. Taihoku. $317 p+50$ plates.

Keller, J. A. (1996). "Fossil flowers and fruits of the Actinidiaceae form the Campanian (Late Cretaceus) of Georgia." American Journal of Botany 83(4): 528-541.

Kramer, P. R. 1939. The woods of Billia, Cashalia, Henoonia, and Juliania. Trop. Woods. 58:1-5. 
Kribs, D. A. 1928. The Persaud collection of British Guiana woods. Trop. Woods. 13:7-46.

Kribs, D. A. 1959. Commercial foreign woods on the American market. Pennsylvania State Univ. 203pp.

Kukachka, B. F. Wood Anatomy of the Neotropical Sapotaceae. Forest Products Laboratory Forest Service. 1978a. Bumelia. Research Paper 1. FPL 325;

Wood Anatomy of the Neotropical Sapotaceae. Forest Products Laboratory Forest Service. 1978b. Mastichodendron. Research Paper 2. FPL 326;

Wood Anatomy of the Neotropical Sapotaceae. Forest Products Laboratory Forest Service. 1978c. Dipholis. Research Paper 3. FPL 327;

Wood Anatomy of the Neotropical Sapotaceae. Forest Products Laboratory Forest Service. 1978 d. Achrouteria. Research Paper 4. FPL 328;

Wood Anatomy of the Neotropical Sapotaceae. Forest Products Laboratory Forest Service. 1978e. Calocarpum. Research Paper 5. FPL 329;

Wood Anatomy of the Neotropical Sapotaceae. Forest Products Laboratory Forest Service. 1978f. Chloroluma. Research Paper 6. FPL 330;

Wood Anatomy of the Neotropical Sapotaceae. Forest Products Laboratory Forest Service. 1978g. Chrysophyllum. Research Paper 7. FPL 331;

Wood Anatomy of the Neotropical Sapotaceae. Forest Products Laboratory Forest Service. 1979a. Diploon. Research Paper 8. FPL 349;

Wood Anatomy of the Neotropical Sapotaceae. Forest Products Laboratory Forest Service. 1979b. Pseudoxythece. Research Paper 9. FPL 350;

Wood Anatomy of the Neotropical Sapotaceae. Forest Products Laboratory Forest Service. 1979c. Micropholis. Research Paper 10. FPL 351;

Wood Anatomy of the Neotropical Sapotaceae. Forest Products Laboratory Forest Service. 1979d. Prieurella. Research Paper 11. FPL 352; 
Wood Anatomy of the Neotropical Sapotaceae. Forest Products Laboratory Forest Service. 1979d. Neoxythece. Research Paper 12. FPL 353;

Wood Anatomy of the Neotropical Sapotaceae. Forest Products Laboratory Forest Service. 1979d. Podoluma. Research Paper 13. FPL 354;

Wood Anatomy of the Neotropical Sapotaceae. Forest Products Laboratory Forest Service. 1980a. Elaeoluma. Research Paper 14. FPL 358;

Wood Anatomy of the Neotropical Sapotaceae. Forest Products Laboratory Forest Service. 1980b. Sandwithiodoxa. Research Paper 15. FPL 359;

Wood Anatomy of the Neotropical Sapotaceae. Forest Products Laboratory Forest Service. 1980c. Paralabatia. Research Paper 16. FPL 360;

Wood Anatomy of the Neotropical Sapotaceae. Forest Products Laboratory Forest Service. 1980d. Gambeya. Research Paper 17. FPL 361;

Wood Anatomy of the Neotropical Sapotaceae. Forest Products Laboratory Forest Service. 1980e. Gomphiluma. Research Paper 18. FPL 362;

Wood Anatomy of the Neotropical Sapotaceae. Forest Products Laboratory Forest Service. 1980f. Chromolucuma. Research Paper 19. FPL 363;

Wood Anatomy of the Neotropical Sapotaceae. Forest Products Laboratory Forest Service. 1981a. Manilkara. Research Paper 20. FPL 371;

Wood Anatomy of the Neotropical Sapotaceae. Forest Products Laboratory Forest Service. 1981b. Barylucuma. Research Paper 21. FPL372;

Wood Anatomy of the Neotropical Sapotaceae. Forest Products Laboratory Forest Service. 1981c. Pradosia. Research Paper 22. FPL 373;

Wood Anatomy of the Neotropical Sapotaceae. Forest Products Laboratory Forest Service. 1981d. Gayella. Research Paper 23. FPL 374;

Wood Anatomy of the Neotropical Sapotaceae. Forest Products Laboratory Forest Service. 1981e. Ecclinusa. Research Paper 24. FPL 395; 
Wood Anatomy of the Neotropical Sapotaceae. Forest Products Laboratory Forest Service. 1981f. Ragala Research Paper 25. FPL 396;

Wood Anatomy of the Neotropical Sapotaceae. Forest Products Laboratory Forest Service. 1981g Myrtiluma. Research Paper 26. FPL 397;

Wood Anatomy of the Neotropical Sapotaceae. Forest Products Laboratory Forest Service. 1981h. Sarcaulus. Research Paper 27. FPL 398;

Wood Anatomy of the Neotropical Sapotaceae. Forest Products Laboratory Forest Service. 1982a. Labatia. Research Paper 28. FPL 416;

Wood Anatomy of the Neotropical Sapotaceae. Forest Products Laboratory Forest Service. 1982b. Eglerodendron. Research Paper 29. FPL 417;

Wood Anatomy of the Neotropical Sapotaceae. Forest Products Laboratory Forest Service. 1982c. Pseudocladia. Research Paper 30. FPL 418;

Wood Anatomy of the Neotropical Sapotaceae. Forest Products Laboratory Forest Service. 1982d. Pouteria Research Paper FPL 31. 419;

Wood Anatomy of the Neotropical Sapotaceae. Forest Products Laboratory Forest Service. 1982e. Richardella Research Paper 32. FPL 420;

Wood Anatomy of the Neotropical Sapotaceae. Forest Products Laboratory Forest Service. 1982f. Englerella. Research Paper 33. FPL 421;

Wood Anatomy of the Neotropical Sapotaceae. Forest Products Laboratory Forest Service. 1982g. Franchetella - Eremoluma. Research Paper 34. FPL 422;

Wood Anatomy of the Neotropical Sapotaceae. Forest Products Laboratory Forest Service. 1982h. Urbanella. Research Paper 35. FPL 422;

Wood Anatomy of the Neotropical Sapotaceae. Forest Products Laboratory Forest Service. 1982i. Syzygiopsis. Research Paper 36. FPL 424.

Lebacq, L. \& Staner, P. 1964. Anatomie comparée des bois d'Amérique latine et d'Afrique centrale. Ann. Mus. Roy. Afr. Cent., Tervuren, Sér. IN-8, Sci. Econ.. no 4. 162pp + 18 plates. 
Lindeman, J. C. \& Mennega, A. M. 1963. Bomenboek voor suriname. Herkenning van Surunaamse hout soorten aan hout en vegetatieve kenmerken. Met tekeningen van W. H. A. Hekking. Uitgave dienst's lands bosbeheer Suriname. Paramaribo. Medelingen van het botanisch museum en herbarium van de Rijksuniversiteit te Utrecht. no 200. 312p.

Maddison, D. R., Maddison, W. 2000. MacClade: analysis of phylogeny and character evolutions. Version 4.0. Sinauer Associates Inc. Sunderland.

Mainieri, C. 1958. Madeiras denominadas caixeta. Inst. Pesq. Tec. Est. São Paulo. Publicação no 572: 1-94.

Mainieri, C. 1978. Fichas de características das madeiras brasileiras. Inst. Pesq. Tec. Est. São Paulo. Publicação oo 966 (120 fichas).

Mainieri, C. \& Chimelo, J. P. 1989. Fichas de características das madeiras brasileiras. $2^{\text {nd }}$ ed. Inst. Pesq. Tec. Est. São Paulo. 418pp.

Marco, H. F. 1933. The wood of Sarcosperma paniculatum Trop. Woods. 33:1-4.

Metcalfe, C. R. \& Chalk, L. 1950. Anatomy of the dicotyledons. Oxford Press. 1499p.

Milanez, F. R. 1934. Estrutura do lenho de Mimusops Huberi. Arq. Inst. Biol. Veg. Rio de Janeiro 1(1):49-62.

Moll. J. W. \& Janssonius, H. H. 1925. Mikrographie des Holzes der auf Java vorkommenden Baumarten. E. J. Brill: Leiden. p 353-412

Morton, C. M., M. W. Chase, et al. (1996). "A molecular evaluation of the monophyly of the order Ebenales based upon rbcL sequence data." Systematic Botany 21(4): 576-586.

Morton, C. M., S. A. Mori, et al. (1997). "Phylogenetic relationships of the Lecythidaceae: a cladistic analysis using rbcL sequence and morphological data." American Journal of Botany 84(4): 530 540.

Nardi Berti, R. \& Edlmann Abbate, M. L. 1988. Legnami tropicali importati in Italia: anatomia e identificazione. I - Africa. Ribera Editore: Milan. 320pp. 
Noshiro, S. and P. Baas (1998). "Systematic wood anatomy of Cornaceae and allies." IAWA Journal 19(1): 43-97.

Pearson, R. S. \& Brown, H. P. 1932. Commercial timbers of India. Their distribution, supplies, anatomical structure, physical and mechanical properties and uses. Central Publication Branch, Government of India, Calcutta. vol. 2. 1150p.

Pennington, T. D. 1990. Flora Neotropica, 52 Sapotaceae. New York Botanical Garden.

Pennington, T. D. 1991. The Genera of Sapotaceae. Royal Botanical Gardens, Kew. 295p.

Record, S. J. 1932. Notes on new species of Brazilian woods. Trop. Woods 31:22-29.

Record, S. J. 1939. American woods of the family Sapotaceae. Trop. Woods 59:21-51.

Record, S. J. \& Hess, R. W. 1943. Timbers of the New World. Yale School of Forestry: New Haven. 640pp.

Record, S. J. and R. W. Hess (1943). Timbers of the new world. New Haven, Yale School of Forestry.

Rizzini, C. T. 1978. Plantas do Brasil. Árvores e Madeiras Úteis do Brasil. Manual de Dendrologia Básica. Editora Edgard Blücher, São Paulo. 300p.

Soerianegara, I \& Lemmens, R. H. M. J. (eds.). 1993. Plant Resourses of South-East Asia PROSEA no 5(1) - Timbers trees: major commercial timbers. Pudoc Scientific Plubishers, Wageningen. 610p.

SUDAM/IPT. 1981. Madeiras da Reserva Florestal de Curuá-Una, Estado do Pará. Caracterização anatômica, propriedades gerais e aplicações. Superint. Desen. Amazônia \& Inst. Pesq. Tec. Est. São Paulo: Belém. 118pp.

Swoford, D. L. 2002. PAUP*. Phylogenetic analysis using parcimony ("and othe methods). Version 4.0b10. Sinauer Associates. Sunderland.

Tortorelli, L. A. 1956. Maderas y bosques argentinos. Editorial Acme, S.A.C.I., Buenos Aires. 910pp. 
Tuset, R. 1963. Descripcion y clave de maderas indigenas del Uruguay. Ministério de Ganaderia y agricultura. Direccion de Agronomia. Departamento de conservacion y desarrollo de los resursos naturals renovables. Division Florestal. o 19. 56pp.

Tuset, R. \& Duran, F. 1970. Descripcion y clave macroscópicas de maderas comerciales en Uruguay. Universidad de la República. Facultad de Agronomia. Boletim no 114. 63pp.

Vitalis-Brun, A. and A. Mariaux (1982). "Séparation anatomique de bois de Sapotacées par des méthodes d'analyse multidimensionnelle." Bois et Frêts des Tropiques 196: 59-71.

Williams, L. 1936. Woods of northeastern Peru. Field Mus. Nat. Hist., Bot. Ser. 15: 1587. Chicago.

Zhang, S.-Y. (1992). "Systematic wood anatomy of the Rosaceae." Blumea 37: 81-158. 
Tabela 2: Dados biometricos do xilema para as especies do genero Manilkara. Espessamento da parede da fibra: (1) paredes pouco espessas; (2) paredes espessas; (3) paredes muito espessas. Largura da linha do parenquima: (1) uma celula de largura; (2) uma a duas celulas de largura; (3) uma a tres celulas de largura; (4) mais de tres celulas de largura. Comprimento da serie parenquimatica: (1) ate oito celulas de comprimento; (2) mais de oito celulas de comprimento. Largura dos raios: (1) raios exclusivamente unisseriados; (2) raios com ate duas celulas de largura; (3) raios com ate tres celulas de largura; (4) raios com mais de quatro celulas de largura. 
Tabela 3: Dados biometricos do xilema para as especies dos generos Sideroxylon e Diploon. Espessamento da parede da fibra: (1) paredes pouco espessas; (2) paredes espessas; (3) paredes muito espessas. Largura da linha do parenquima: (1) uma celula de largura; (2) uma a duas celulas de largura; (3) uma a tres celulas de largura; (4) mais de tres celulas de largura. Comprimento da serie parenquimatica: (1) ate oito celulas de comprimento; (2) mais de oito celulas de comprimento. Largura dos raios: (1) raios exclusivamente unisseriados; (2) raios com ate duas celulas de largura; (3) raios com ate tres celulas de largura; (4) raios com mais de quatro celulas de largura. 
Tabela 4: Dados biometricos do xilema para as especies do genero Micropholis. Espessamento da parede da fibra: (1) paredes pouco espessas; (2) paredes espessas; (3) paredes muito espessas. Largura da linha do parenquima: (1) uma celula de largura; (2) uma a duas celulas de largura; (3) uma a tres celulas de largura; (4) mais de tres celulas de largura. Comprimento da serie parenquimatica: (1) ate oito celulas de comprimento; (2) mais de oito celulas de comprimento. Largura dos raios: (1) raios exclusivamente unisseriados; (2) raios com ate duas celulas de largura; (3) raios com ate tres celulas de largura; (4) raios com mais de quatro celulas de largura. 
Tabela 5: Dados biometricos do xilema para as especies dos generos Chromolucuma, Sarcaulus e Elaeoluma. Espessamento da parede da fibra: (1) paredes pouco espessas; (2) paredes espessas; (3) paredes muito espessas. Largura da linha do parenquima: (1) uma celula de largura; (2) uma a duas celulas de largura; (3) uma a tres celulas de largura; (4) mais de tres celulas de largura. Comprimento da serie parenquimatica: (1) ate oito celulas de comprimento; (2) mais de oito celulas de comprimento. Largura dos raios: (1) raios exclusivamente unisseriados; (2) raios com ate duas celulas de largura; (3) raios com ate tres celulas de largura; (4) raios com mais de quatro celulas de largura. 
Tabela 6: Dados biometricos do xilema para as especies dos generos Ecclinusa e Pradosia. Espessamento da parede da fibra: (1) paredes pouco espessas; (2) paredes espessas; (3) paredes muito espessas. Largura da linha do parenquima: (1) uma celula de largura; (2) uma a duas celulas de largura; (3) uma a tres celulas de largura; (4) mais de tres celulas de largura. Comprimento da serie parenquimatica: (1) ate oito celulas de comprimento; (2) mais de oito celulas de comprimento. Largura dos raios: (1) raios exclusivamente unisseriados; (2) raios com ate duas celulas de largura; (3) raios com ate tres celulas de largura; (4) raios com mais de quatro celulas de largura. 
Tabela 7: Dados biometricos do xilema para as especies do genero Pouteria. Espessamento da parede da fibra: (1) paredes pouco espessas; (2) paredes espessas; (3) paredes muito espessas. Largura da linha do parenquima: (1) uma celula de largura; (2) uma a duas celulas de largura; (3) uma a tres celulas de largura; (4) mais de tres celulas de largura. Comprimento da serie parenquimatica: (1) ate oito celulas de comprimento; (2) mais de oito celulas de comprimento. Largura dos raios: (1) raios exclusivamente unisseriados; (2) raios com ate duas celulas de largura; (3) raios com ate tres celulas de largura; (4) raios com mais de quatro celulas de largura. 
Continuacão da Tabela 7: Dados biometricos do xilema para as especies do genero Pouteria. Espessamento da parede da fibra: (1) paredes pouco espessas; (2) paredes espessas; (3) paredes muito espessas. Largura da linha do parenquima: (1) uma celula de largura; (2) uma a duas celulas de largura; (3) uma a tres celulas de largura; (4) mais de tres celulas de largura. Comprimento da serie parenquimatica: (1) ate oito celulas de comprimento; (2) mais de oito celulas de comprimento. Largura dos raios: (1) raios exclusivamente unisseriados; (2) raios com ate duas celulas de largura; (3) raios com ate tres celulas de largura; (4) raios com mais de quatro celulas de largura. 
Continuacão da Tabela 7: Dados biometricos do xilema para as especies do genero Pouteria. Espessamento da parede da fibra: (1) paredes pouco espessas; (2) paredes espessas; (3) paredes muito espessas. Largura da linha do parenquima: (1) uma celula de largura; (2) uma a duas celulas de largura; (3) uma a tres celulas de largura; (4) mais de tres celulas de largura. Comprimento da serie parenquimatica: (1) ate oito celulas de comprimento; (2) mais de oito celulas de comprimento. Largura dos raios: (1) raios exclusivamente unisseriados; (2) raios com ate duas celulas de largura; (3) raios com ate tres celulas de largura; (4) raios com mais de quatro celulas de largura. 
Continuacão da Tabela 7: Dados biometricos do xilema para as especies do genero Pouteria. Espessamento da parede da fibra: (1) paredes pouco espessas; (2) paredes espessas; (3) paredes muito espessas. Largura da linha do parenquima: (1) uma celula de largura; (2) uma a duas celulas de largura; (3) uma a tres celulas de largura; (4) mais de tres celulas de largura. Comprimento da serie parenquimatica: (1) ate oito celulas de comprimento; (2) mais de oito celulas de comprimento. Largura dos raios: (1) raios exclusivamente unisseriados; (2) raios com ate duas celulas de largura; (3) raios com ate tres celulas de largura; (4) raios com mais de quatro celulas de largura. 
Continuacão da Tabela 7: Dados biometricos do xilema para as especies do genero Pouteria. Espessamento da parede da fibra: (1) paredes pouco espessas; (2) paredes espessas; (3) paredes muito espessas. Largura da linha do parenquima: (1) uma celula de largura; (2) uma a duas celulas de largura; (3) uma a tres celulas de largura; (4) mais de tres celulas de largura. Comprimento da serie parenquimatica: (1) ate oito celulas de comprimento; (2) mais de oito celulas de comprimento. Largura dos raios: (1) raios exclusivamente unisseriados; (2) raios com ate duas celulas de largura; (3) raios com ate tres celulas de largura; (4) raios com mais de quatro celulas de largura. 
Continuacão da Tabela 7: Dados biometricos do xilema para as especies do genero Pouteria. Espessamento da parede da fibra: (1) paredes pouco espessas; (2) paredes espessas; (3) paredes muito espessas. Largura da linha do parenquima: (1) uma celula de largura; (2) uma a duas celulas de largura; (3) uma a tres celulas de largura; (4) mais de tres celulas de largura. Comprimento da serie parenquimatica: (1) ate oito celulas de comprimento; (2) mais de oito celulas de comprimento. Largura dos raios: (1) raios exclusivamente unisseriados; (2) raios com ate duas celulas de largura; (3) raios com ate tres celulas de largura; (4) raios com mais de quatro celulas de largura. 
Tabela 8: Dados biometricos do xilema para as especies do genero Chrysophyllum. Espessamento da parede da fibra: (1) paredes pouco espessas; (2) paredes espessas; (3) paredes muito espessas. Largura da linha do parenquima: (1) uma celula de largura; (2) uma a duas celulas de largura; (3) uma a tres celulas de largura; (4) mais de tres celulas de largura. Comprimento da serie parenquimatica: (1) ate oito celulas de comprimento; (2) mais de oito celulas de comprimento. Largura dos raios: (1) raios exclusivamente unisseriados; (2) raios com ate duas celulas de largura; (3) raios com ate tres celulas de largura; (4) raios com mais de quatro celulas de largura. 
Continuaç̃o da Tabela 8: Dados biometricos do xilema para as especies do genero Chrysophyllum. Espessamento da parede da fibra: (1) paredes pouco espessas; (2) paredes espessas; (3) paredes muito espessas. Largura da linha do parenquima: (1) uma celula de largura; (2) uma a duas celulas de largura; (3) uma a tres celulas de largura; (4) mais de tres celulas de largura. Comprimento da serie parenquimatica: (1) ate oito celulas de comprimento; (2) mais de oito celulas de comprimento. Largura dos raios: (1) raios exclusivamente unisseriados; (2) raios com ate duas celulas de largura; (3) raios com ate tres celulas de largura; (4) raios com mais de quatro celulas de largura. 
Costa, A. 2006

Gênero Manilkara

9. Pranchas 
